\title{
A geosim analysis of ship resistance decomposition and scale effects with the aid of CFD
}

\author{
Momchil Terziev $^{1 *}$, Tahsin Tezdogan ${ }^{1}$, Atilla Incecik ${ }^{2}$ \\ ${ }^{1}$ Department of Naval Architecture, Ocean and Marine Engineering, Henry Dyer Building, \\ University of Strathclyde, 100 Montrose Street, Glasgow G4 OLZ, UK \\ ${ }^{2}$ University of Strathclyde, Faculty of Engineering, Glasgow, UK \\ *Corresponding author: momchil.terziev@strath.ac.uk
}

\begin{abstract}
Historically, the prediction ship resistance has received its fair share of attention by the scientific community. Yet, a robust scaling law still lacks, leaving testing facilities to rely on experience-based approaches and large datasets accumulated from years of operation. Academia's concern regarding this has not led to an extrapolation procedure, capable of bearing scrutiny adequately. One way to circumvent what has become the bane of the study of ship resistance is to perform Reynolds averaged Navier-Stokes (RANS) simulations directly in full-scale. The rapid advent of such methods has meant that confidence levels in predictions achieved by RANS simulations are low. This paper explores and demonstrates scale effects on the constituent components of ship resistance by performing a geosim analysis using a Computational Fluid Dynamics approach. Emphasis is placed on challenging the assumptions imposed as part of the currently accepted ship resistance extrapolation procedure. Our results suggest that a high degree of uncertainty exists in the calculated full-scale resistance depending on the approach taken towards its evaluation. In particular, scale effects are demonstrated in wave resistance, while free surface effects are palpable in the frictional resistance.
\end{abstract}

Keywords: ship resistance; scale effects; wave resistance; form factor; geosim; CFD

\section{Introduction}

When designing a ship, its performance is usually assessed against a variety of parameters. One of these is the expected value of resistance that the ship will experience in deep, calm waters. Having a good estimate of this value is crucial because it determines many characteristics of the ship, such as the power delivered by the propulsion plant. In some cases, the naval architect may choose to seek alternative hull forms if the resistance falls within an unfavourably high range.

In 2011, the International Maritime Organisation (IMO) introduced the first mandatory measure since the Kyoto Protocol (UNFCCC, 1998) to improve the energy efficiency of ships and accelerate innovation in the maritime sector (IMO, 2011). This regulation requires every ship that has been built after January $1^{\text {st }} 2013$ to be certified using the Energy Efficiency Design Index (EEDI). EEDI can be broadly thought of as a measure of the energy efficiency per tonnemile. As such, ship resistance is one of the primary parameters used in its calculation. Hou et al. (2019) discussed the two sources of uncertainty that arise when calculating the EEDI of a 
ship: aleatory uncertainty, which exists objectively due to the operating environment, for example; and epistemic uncertainty, which relates to lack of knowledge. Here, we will examine the latter only.

The source of epistemic uncertainty lies with the complexity of estimating ship resistance - a problem that remains unsolved despite the fact that scientists have been attempting to overcome it for several centuries. For instance, Gotman (2007) reported that both Newton and Euler had devised approximations based on different mathematical approaches. Even with the advent of Computational Fluid Dynamics (CFD) methods, we cannot guarantee that a calculated value for the resistance of a ship will match our experiments. Instead, the uncertainty is estimated and reported on, for knowledge of the exact value of the error would allow us to simply correct our results accordingly. For this reason, expensive experiments are routinely performed in towing tanks around the world.

While one is free to geometrically scale down a ship to a convenient size, the physical properties of water do not change (Tropea et al., 2007). Therefore, the troubles of the naval architect do not end once the experiment has run its course. We may only keep the ratio of inertial and viscous forces (the Reynolds number $-R e$ ), or the ratio of gravitational and inertial forces (the Froude number $-F r$ ) the same between model and ship (Lee et al., 2018). Extrapolation procedures have been devised to keep these ratios, the earliest by William Froude in the 1870s (Molland et al., 2017). Theoretically, these allow us to predict the resistance of the full-scale ship using a model experiment in any scale.

The present study will attempt to establish a better understanding of the epistemic uncertainty involved in calculating full-scale ship resistance using a Reynolds Averaged Navier-Stokes (RANS) solver. To achieve the task at hand, experimental data for the well-known KCS hull form in three different scale factors were collected. At each scale factor, numerical simulations are performed in three different ways to predict the components of bare hull resistance. Specifically, the ship is scaled geometrically and simulated in both double body and multiphase conditions. Additionally, by modifying the value of dynamic viscosity only, the ship's Reynolds number is changed to match its respective value at higher scale factors without a change in characteristic length.

The novelty of this study is expressed in the unique approach adopted to predicting ship resistance. While a plethora of researchers have examined scale effects in the present context, to the best of our knowledge, none have performed this with a variety of methods incorporating all physical phenomena, simultaneously validating numerical predictions against experimental data. Specifically, the adopted methodology enables us to predict interactions between the linearly decomposed components of ship resistance and examine scale effects on each individually.

Of particular interest is wave resistance, which is typically assumed scale invariant. Although the work of Raven et al. (2008) suggested otherwise, this assumption is still applied widely. In this context, the present paper will seek to confirm and further examine the presence of scale effects in wave resistance in an attempt to stimulate more research in this area.

The remainder of this work, first, reviews the current practices and justifies the adopted research methodology in sections 2 and 3, respectively. Then, the numerical modelling is presented in section 5 , before the resulting data is shown in section 6 , accompanied by a 
discussion on its significance. Finally, section 7 provides suggestions for future research and conclusions.

\section{Background}

The earliest procedure for ship extrapolation was devised by Froude (1874). It begins by assuming that ship resistance, in non-dimensional form, can be decomposed into frictional and residuary components. Central to the present argument is the latter being constant with scale, which is known not to be correct (Toki, 2008). On the other hand, the frictional components vary with $R e$, and can be estimated by the skin friction of a flat plate with an equivalent submerged surface.

The second and more widely used approach was proposed by Hughes (1954), who suggested the form factor approach. Within this approach, the resistance is decomposed into viscous and wave-making components. The latter is hypothesised to remain constant, because, at any scale, the ship is expected to produce a geometrically similar wave pattern. On the other hand, viscous resistance is further split into frictional and viscous pressure components by use of the form factor. Again, the frictional resistance is equal to that of an equivalent flat plate. Several problems plague this method, the most important of which is perhaps that the form factor $(1+k)$, used in accounting for 3D effects, is assumed invariant with scale. To estimate $(1+k)$, a model is towed at a low speed, where the wave resistance is supposed to be negligible. Alternatively, the ITTC78 method introduces a factor to be determined via regression analysis to account for the wave resistance in the form factor calculation, shown in Eq. (1):

$C_{T}=(1+k) C_{F}+c F_{r}^{N}$

Where $c$ is a constant, chosen to fit as many $C_{T}$ measurements as possible, while $N$ normally attains a value between 4 and 6 (van Mannen and van Oossanem, 1988).

Although the here described procedures, summarised graphically in Figure 1, can provide a good estimate of the resistance prediction, they are just that - estimates. We expect differences to stem from a variety of sources. The obvious ones are associated with the assumptions mentioned above: in the first case, the residuary resistance, whereas in the second - the wave resistance, both assumed constant with scale. More fundamentally, there is no physical mechanism or law requiring that resistance should be decomposed in either of the two ways described.

The problem becomes worse because, while a linear decomposition is assumed, it is wellknown that resistance is a nonlinear problem (van Mannen and van Oossanem, 1988). Furthermore, we fall within the category of processes in which linearly breaking up physical phenomena and treating each part separately cannot adequately describe reality. This is due to the inability of linear systems to account for interactions between the different components in a nonlinear system, yielding properties not exhibited by our linear system (Saaty and Bram, 1964). An example of this problem is the interaction between frictional and wave resistance, as will be demonstrated later.

Underpinning the field of engineering is dimensional analysis, defined by White (2010) as the practice of reducing the number and complexity of variables upon which a physical process depends. Consequently, dimensional analysis rests on our ability to define proper relationships between variables. Having established our inability to achieve this fully implies that we can 
never predict exactly the full-scale resistance of a ship with precision, using model experiments. To tackle this, towing tank facilities rely on experience and large databases of model and full-scale data recorded during sea trials.
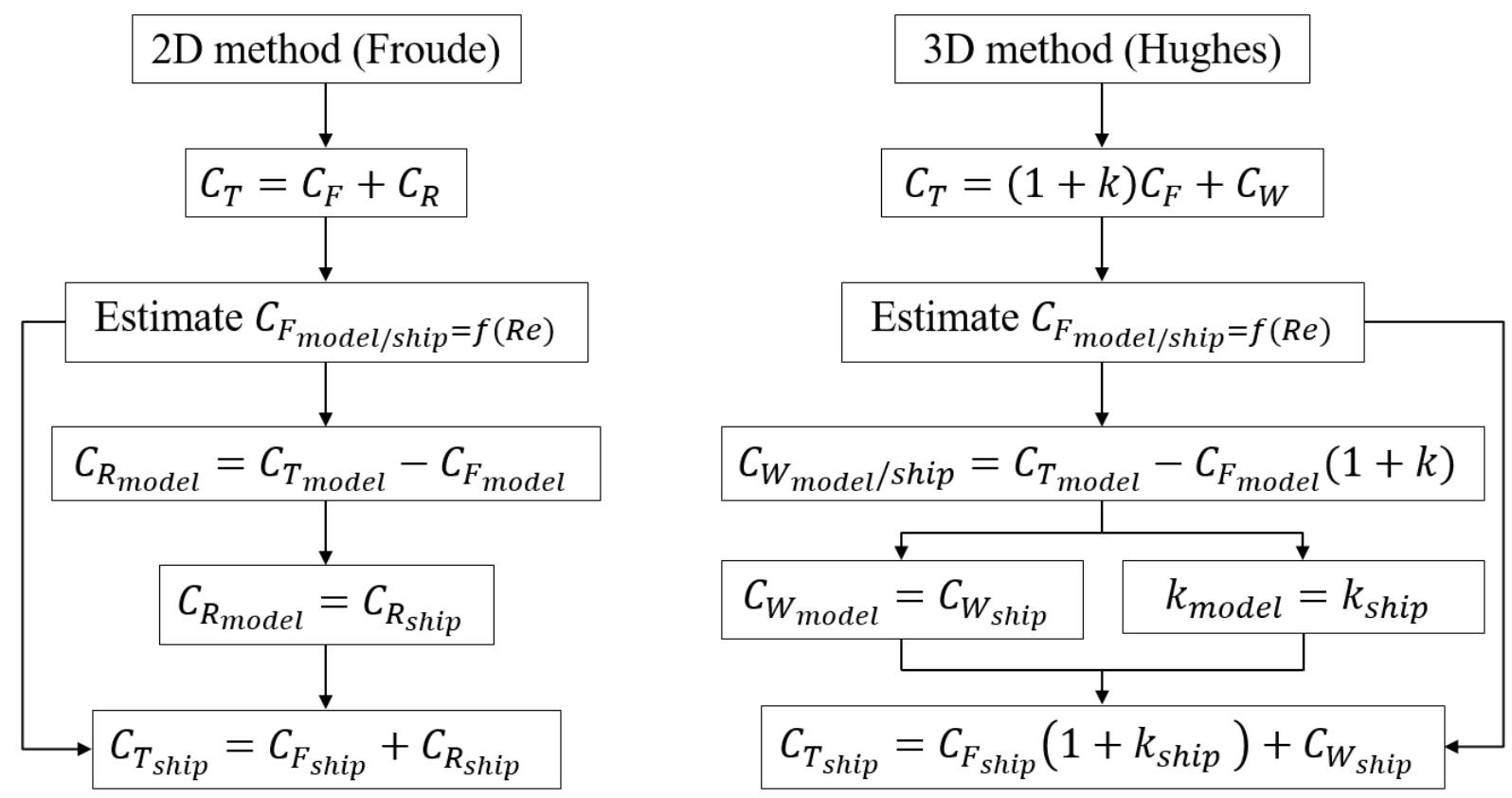

Figure 1. Resistance extrapolation

On the other hand, CFD methods, discussed later in this section, present the possibility of accounting for all properties of the fluid flow, unlike potential methods. Here, resistance is defined as the addition of tangential and normal components, which is a more physically sound approach. However, we should keep in mind the limitations we are currently facing, which include the statistical modelling of turbulence (Durbin and Pettersson Reif, 2011), discussed in Section 5 .

In his experiments, García-Gómez (2000) demonstrated changes in resistance as a result of scaling on several different hull forms. He also suggested an empirical correction to account for the difference in the model and full-scale ship form factors. It is important to note that according to García-Gómez, (2000), scale effects are due to Reynolds number-dependency only, and they stem from the friction line used. In this paper, we will make use of twelve different methods of estimating the frictional resistance coefficient. Additionally, a variety of methods, described in Molland et al., (2017), used to calculate the form factor, will be tested. The empirical correction of García-Gómez (2000) will also be applied and tested to establish its performance.

Methods to calculate the frictional resistance coefficient can be classified into three categories. These include correlations, defining $C_{F}$ as a function of $R e$, such as that of White (2006), as well as Prandtl-Schlichting and Schultz-Grunow, as reported in (Schlichting 1979). The second category consists of formulae, derived using integrated analytical two dimensional boundary layer equations expressing the local frictional resistance of a flat plate, such as those of Schoenherr (1932), Hughes (1954), Grigson (1999), Katsui et al. (2005), and Lazauskas (2009). The third category is numerical lines, such as those of Eça and Hoekstra (2008), who developed three formulations by fitting curves to data obtained via a RANS solver - one based on the of Hughes (1954) line (in rational form); and two in polynomial form (one linear and one cubic). 
In this study, we will use the cubic fit presented by Eça and Hoekstra (2008), as it showed the best agreement with experiments. In their study, Wang et al. (2015) also derived two numerical lines, both of which will be used in this study to compare the obtained results.

While there is a plethora of competing friction lines, it is important to keep in mind that the vast majority do not take into account free-surface effects. The analytically derived ones use the integral value of two-dimensional boundary layer equations to express the friction coefficient. Even the numerical friction lines were established with the use of double body models. However, as pointed out by Stern (1985), the presence of a free surface causes a highly complex three-dimensional flow. Thus, not only do we expect differences due to the presence of a free surface in the frictional coefficient, but also, the wave resistance is modified as a result of the different nature of the boundary layer (Marquardt, 2009). To account for viscous effects, researchers have used the 'effective' ship hull, which is the ship geometry, plus the boundary layer thickness. The hypothesis, then, suggests that wave resistance can be calculated more accurately. Lazauskas (2009) showed that improvement can be achieved in the wave resistance evaluation by modifying Michell's (1898) integral to express this. Alternatively, Gotman (2002) separated the monotone part from the oscillatory part of the integral and incorporated viscous effects, achieving great improvement. Unfortunately, there are no established software packages capable of modelling an 'effective' ship hull, nor are there any using Gotman's (2002) solution. Therefore, we are restricted to the use of the more classical version of the abovementioned integral.

So far, we have mentioned primarily analytical and experimental works. However, an approach of rapidly emerging popularity is the use of CFD. Some of the early works in which scale effects using a CFD approach have been examined include the work of Oh and Kang (1992). They modelled viscous flow over the stern of a ship by invoking the double body approximation. According to Gotman (2007), Foettinger first described the double body idea by replacing the free surface with a symmetry boundary in 1924. Since then, tests in wind tunnels using the underwater shape of a ship and its mirror image have been performed, for example by Patel and Sarda (1990). They studied the turbulence and boundary layer characteristics of the Wigley parabolic hull. The contribution of the abovementioned work is that it describes features of the 3D flow used for numerical turbulence modelling.

Researchers were constrained for several years to modelling only a part of a ship hull. Using the double body approach and placing the inlet amidships, Eca and Hoekstra (2001) predicted the scale effect on tanker by varying the Reynolds number. One of the problems highlighted in their study is the scarcity of experimental data for comparison. Although the problem is still unresolved today, Kim et al. (2001) performed a systematic series of experiments to alleviate this. Their motivation for performing the study was specifically to provide validation data for CFD codes. Later, Tahara et al. (2002) investigated the appropriate numerical setup applicable to full-scale ship hydrodynamic performance prediction. Their findings include that one of the key issues "for full scale ship flow simulation is to maintain the accuracy in the resolution of the flow within a viscous and turbulent boundary layer of decreasing thickness."

Turbulence modelling has been shown to be one of the main factors in modelling scale effects. Duvigneau et al. (2003) performed a study on hull form optimisation in both model and fullscale. Their findings indicate the calculated parameters are highly dependent on the turbulence model chosen. Indeed, Visonneau (2005) reported the same finding within the European Full- 
scale Flow Research and Technology (EFFORT) project (Bugalski, 2007). He also pointed towards free-surface effects as a potential source of difficulties for RANS solvers in full scale. However, the main problem remains the lack of full-scale data for validation and verification.

Later, Raven et al. (2008) examined the capabilities of an inviscid solver and a viscous solver to predict the full-scale performance of a ship. They found that the wave resistance coefficient is up to $20 \%$ higher in full-scale when compared to model-scale. However, the scaling of viscous resistance was computed via a double body model. Continuing the trend of using the double body method, Kouh et al. (2009) demonstrated the Reynolds number dependence of the form factor. Their study features several hull forms, including the KCS, which allowed them to draw comparisons between different shapes.

Min and Kang (2010) questioned the basic assumptions of the extrapolation procedure recommended by the ITTC (2017). Their paper represents the end of the sequence of studies confirming that the form factor is Reynolds number-dependent. However, they went further: they suggest the form factor to be treated as a function of Froude number as well, and call on researchers to investigate this. Min and Kang (2010) also provided a correction formula to be used in the determination of the form factor, which will be employed to determine its efficacy in the present study.

An interesting approach to resolving the scaling problem was presented by Guo et al. (2015), who used a non-geometrically similar approach, namely, a similar ship, whose flow characteristics at model-scale match the parent hull in full-scale is selected. Although this method would be very useful if refined, it has yet to be implemented elsewhere.

As recently as 2016, researchers opted to use the double body method to study ship performance. For instance, Wang et al. (2016) chose this approach to study the effect of different draughts on the form factor. However, the main event of 2016 in this respect was the publication of the Lloyd's register workshop on ship scale hydrodynamics (Ponkratov, 2016), in which the problems of CFD predictions in full-scale can be seen more easily. Although we will limit our attention to the bare-hull submissions, it is worth noting that only 3 participants achieved an acceptable level of accuracy (3\% deviation). For the purposes of the workshop, sea trials were conducted post-docking of a general cargo ship between Istanbul and Varna. The results indicate that air resistance (cranes and superstructure) plays a much more important role in the total resistance (7\% contribution) than trim (3\% contribution). The Ponkratov (2016) report highlights the differences between numerical setups. For instance, Starke et al. (2017), who were one of the participants, showed that a level-set method for free surface capturing is not capable of modelling the overturning bow wave.

The main obstacles to be overcome prior to the routine use of CFD in full-scale computations require further research as suggested by the literature. One of the issues frequently pointed out is the large number of cells. However, Tezdogan et al. (2015) demonstrated that it is possible to carry out simulations directly in full-scale. Alternatively, Haase et al. (2016) proposed to verify a numerical grid in model-scale (based on Froude similarity). Then, by altering the value of viscosity, the Reynolds number can be changed to match the corresponding full-scale ship. In this study, an attempt will be made to re-create this type of scaling and assess its performance for the KCS. 


\section{Methodology}

As mentioned in Section 1, the adopted methodology revolves around the capabilities of Star$\mathrm{CCM}+$, a commercially available RANS solver. Making this choice allows us to exploit the versatility inherent in numerical simulations. In reality, we are limited to performing 'multiphase experiments', unless we use the underwater shape of a ship and its mirror image in a wind tunnel. Both Section 2, and the wider literature suggest that such experiments are extremely rare, even in an academic context. However, numerically, not only is this a possibility, but it is an approach capable of substantially accelerating convergence characteristics of the numerical solution.

In particular, some aspects of a simulation requiring attention are the decay of ship motions (in steady state cases) and the convergence of the wave field. In other words, the wave pattern must become invariant with respect to the ship. Invoking the double body assumption implies replacing the free surface with a symmetry plane as well as eliminating the rigid body motions of the ship. This is the main reason why the earlier works cited in Section 2 use the double body approach: insufficient computational power to fully simulate the flow field and ship motions. Naturally, deviating from the actual physics of the problem examined renders our predictions less reliable.

Keeping in mind the inherent consequences present in performing simulations under the double body assumption, we should also mention why applying it in this study is beneficial. The resistance decomposition of a ship according to the ITTC (2017) is shown in Eq. (2):

$C_{T}=(1+k) C_{F}+C_{W}$

Where $(1+k)$ is the form factor, while $C_{T}, C_{F}$, and $C_{W}$ are the total, frictional, and wave resistance coefficients, respectively. These constitute the measured force, non-dimensionalised by $0.5 \rho S V^{2}$, where $\rho\left(988.8 \mathrm{~kg} / \mathrm{m}^{3}\right)$ is the fresh water density, $S$ is the wetted surface area in $\mathrm{m}^{2}$, and $V$ is the ship speed in $\mathrm{m} / \mathrm{s}$.

Replacing the free surface with a non-deformable symmetry plane renders $C_{W}=0$, therefore Eq. (2) becomes $C_{T}=(1+k) C_{F}=C_{V P}+C_{F}$, where $C_{V P}$ is the viscous pressure resistance coefficient. This matches the resistance definition in all RANS solvers. Namely, the total resistance is the sum of tangential and normal components. In multiphase simulations, RANS solvers compute the total as $C_{T}=C_{P}+C_{F}$, where $C_{P}$ is the pressure resistance. Clearly, all components are interrelated and calculating each presents its own challenges. Here, we can avoid relying on methods, whether potential (in the case of $C_{W}$ ) or otherwise (for $(1+k)$ and $C_{F}$ ), to predict their value by defining the wave resistance coefficient as shown in Eq. (3) and form factor in Eq. (4):

$$
\begin{aligned}
& C_{W}=C_{T_{\text {multiphase }}}-C_{T_{\text {double body }}} \\
& (1+k)=C_{T_{\text {double body }}} / C_{F_{\text {double body }}}
\end{aligned}
$$

The definitions of Eq. (3) and (4) are used in this study to predict scale effects on each component of ship resistance. 
Additionally, seeking to confirm our assertion that sinkage and trim do not contribute much to the total resistance in deep waters, double body simulations are run in both level and translated conditions, the latter matching the multiphase orientation of the ship. To isolate Reynolds number effects on resistance coefficients and the form factor, throughout this study a single Froude number is used ( $F r=0.26$, which corresponds to the service condition), chosen to match available experimental data.

Finally, an explanation is owed to our assertion that a change fluid viscosity can be used to scale the ship without altering its dimensions. In the present study, the term 'viscous scaling' is used to describe the altering of the value of dynamic viscosity $(\mu)$ that changes the Reynolds number. This approach was adopted following Haase et al. (2016), where it was applied on a catamaran. The method relies on verifying the mesh in model-scale versus experiments and changing the viscosity value to match the full-scale $R e$. Here, we perform this in steps, which match the examined scale factors to more accurately gauge its performance. We will only apply it on the double body simulations after the orientation of the ship has been adjusted according to the running trim and the sinkage, calculated using the multiphase approach. Naturally, the most economical simulations are sought in terms of computational power and time. For this reason viscous scaling is applied to the hull form in the $75^{\text {th }}$ scale. Therefore, the values for $\mu$ shown in Table 1 correspond to those needed to make the $\operatorname{Re}{ }^{(75)}$ match $\operatorname{Re}{ }^{(52.676)}, \operatorname{Re}^{(31.599)}$ and $R e^{(1)}$, where the bracketed superscripts indicate the scale factor $\left(R e^{(\lambda)}\right)$. To account for the geometric scaling, all results are multiplied by $\lambda^{3}$ (Haase et al., 2016). To elaborate, the resistance values are multiplied by the ratio of scale factors, raised to the third power. Specifically, using $\lambda=75 \rightarrow \lambda=31.599$ as an example, after modifying $\mu$ according to the value shown in Table $1\left(\mu^{(31.599)}=2.431 \times 10^{-4} \mathrm{~Pa}-\mathrm{s}\right)$ we would multiply each constituent component of the measured resistance by $(75 / 31.599)^{3}=13.371$ at the end of the simulation. This procedure is applied analogously at each scale factor examined.

\section{Ship geometry and conditions}

There are many examples of research that attempt to resolve the ship scaling problem. Some significant contributions to the field were discussed in the previous sections. Here, we aim to elaborate on the selected case-studies.

The best way to determine scaling effects is to test the same ship at different scales while measuring parameters of interest. By doing this, the scope is limited to a single hull form, and therefore, it would put into question the generalisations that we might be tempted to make about other hulls forms. Still, the literature on this subject suggests that incorporating multiple hull forms is not advantageous. For instance, García-Gómez (2000), Min and Kang, (2010), and Lee et al. (2018) showed scattering in results produced by different hull forms, even when considering non-dimensional quantities, such as the form factor. Although we are by no means insured against the same outcome, it is maintained that a more in-depth study is possible considering a single hull form.

The only choices worth considering in detail in terms of hull forms are those created for numerical benchmark purposes. From the large number of experiments conducted on them in different scale factors, the most attractive proves to be the KCS, because resistance measurements (for $F r=0.26$ ) have been performed in a scale factor $(\lambda)$ of 75 by Shivachev et al. (2017), 52.667 by Simonsen et al., (2013) and 31.599 by Kim et al. (2001). Table 1 shows the principal dimensions and case-studies in each scale. Here, the value of dynamic viscosity 
in the $75^{\text {th }}$ scale is in bold to highlight it as the default value for the simulations. By contrast, viscous scaling has been performed in the places where other values are listed.

Table 1. KCS Principal characteristics and case-studies

\begin{tabular}{|c|c|c|c|c|c|c|}
\hline Quantity & Symbol & & $\mathrm{Va}$ & & & Unit \\
\hline Scale factor & $\lambda$ & 1 & 31.599 & 52.667 & 75 & - \\
\hline Length & $\mathrm{L}$ & 230 & 7.279 & 4.367 & 3.067 & $\mathrm{~m}$ \\
\hline Beam & $\mathrm{B}$ & 32.2 & 1.019 & 0.611 & 0.429 & $\mathrm{~m}$ \\
\hline Depth & $\mathrm{D}$ & 19 & 0.601 & 0.361 & 0.253 & $\mathrm{~m}$ \\
\hline Draught & $\mathrm{T}$ & 10.8 & 0.342 & 0.205 & 0.144 & $\mathrm{~m}$ \\
\hline Displacement & $\nabla$ & 51990.120 & 1.649 & 0.356 & 0.123 & $\mathrm{~m}^{3}$ \\
\hline Block coefficient & $\mathrm{C}_{\mathrm{B}}$ & 0.6505 & 0.651 & 0.651 & 0.651 & - \\
\hline Wetted area with rudder & $\mathrm{S}$ & 9539 & 9.553 & 3.439 & 1.696 & $\mathrm{~m}^{2}$ \\
\hline Longitudinal rentre of gravity & LCG & 111.603 & 3.532 & 2.119 & 1.488 & $\mathrm{~m}$ \\
\hline Vertical centre of gravity & VCG & 7.28 & 0.230 & 0.138 & 0.097 & $\mathrm{~m}$ \\
\hline Metacentric height & $\mathrm{GM}_{\mathrm{T}}$ & 0.6 & 0.019 & 0.011 & 0.008 & $\mathrm{~m}$ \\
\hline Velocity & $\mathrm{V}$ & 12.350 & 2.196 & 1.702 & 1.426 & $\mathrm{~m} / \mathrm{s}$ \\
\hline Froude number & $F r$ & 0.26 & 0.26 & 0.26 & 0.26 & - \\
\hline Reynolds number & $R e$ & $3.188 \times 10^{9}$ & $1.794 \times 10^{7}$ & $8.342 \times 10^{6}$ & $4.909 \times 10^{6}$ & - \\
\hline Dynamic viscosity for scaling & $\mu$ & $1.368 \times 10^{-6}$ & $2.431 \times 10^{-4}$ & $5.229 \times 10^{-4}$ & $8.887 \times 10^{-4}$ & Pa-s \\
\hline
\end{tabular}

\section{Numerical set-up}

In this section, the relevant details regarding the numerical setup are discussed. Prevalence is given to parameters likely to affect the computed results. Where possible, a discussion is included on the potential effect each decision could have on the outcomes of the study.

\subsection{Physics modelling}

The RANS solver used, Siemens' Star-CCM+, version 13.4.011, employs a Finite Volume Method (FVM) to discretise the integral form of the Navier-Stokes equations. Continuity and momentum are linked via a predictor-corrector scheme.

As alluded to in Section 2, turbulence modelling is suspected to play a crucial part in scale effects. For the purposes of the present study, the realisable $\kappa-\varepsilon$ turbulence model with the all $y^{+}$wall treatment is used. There are several advantages of selecting this two-equation turbulent kinetic energy-dissipation model. Primarily, our interests lie in accuracy and economy. The findings of Larsson et al. (2014) indicate that there is no discernable change in resistance predictions with more complex models. On the other hand, Salim and Cheah (2009) performed systematic RANS simulations using ANSYS on the frictional resistance of a flat plate and compared their results with a variety of turbulence models. The $\kappa-\varepsilon$ model was shown to deliver better predictions than the $\kappa-\omega$ model, provided that the viscous sublayer is resolved. In other words, the $y^{+}$value should be lower than 1 . Indeed, the accuracy of the result depends strongly on our ability to maintain $y^{+}<1$.

Eça et al. (2015) showed that values of $y^{+}$within the buffer zone may lead to an error in the region of $10 \%$ when calculating the frictional resistance. For grids featuring cells within the viscous sublayer $\left(y^{+}<1\right)$, a single difficulty is reported by both Eça et al. (2015) and the ITTC 
(2011): large number of high-aspect-ratio cells, which make convergence problematic. In other words, resistance predictions are vastly superior in terms of accuracy when $y^{+}<1$ is maintained over the wetted area of the ship, as long as convergence is not compromised. Stern et al. (2013) reported that a challenge for full-scale computations would be the number of near-wall cells. Indeed, Piomelli and Balaras (2002) predicted that wall-normal cell numbers would have to vary with $R e^{0.4}$ only within the outer boundary layer. Thus, the $y^{+}$value is allowed to exceed unity in full-scale due to the prohibitively large cell number needed otherwise.

The $\kappa-\varepsilon$ turbulence model, widely used for full-scale flows (Schweighofer, 2004; Tezdogan et al., 2016a), is also advantageous due to its relative computational economy. Quérard et al. (2008) found that a reduction of up to $25 \%$ in computational time is possible compared to more sophisticated models. Furthermore, the simulations of Simonsen et al. (2013) were performed using the $\kappa-\omega$ model in Star-CCM+ and CFDSHIP-IOWA, which will allow comparison of turbulence models.

In the case of multiphase simulations, the Volume of Fluid (VOF) method, introduced by Hirt and Nichols (1981), is used to model the free surface, and the movement of the water. This is done via the flat wave concept. The VOF method describes the two phases by assigning a scalar value of 0 to air and 1 to water. The interface between the two, i.e. cells containing equal parts of air and water attain a value of 0.5. Therefore, the inlet and outlet boundaries have a field function associated with them. At the inlet, the velocity and direction of the flat wave is specified, whereas the outlet is set to maintain the hydrostatic pressure. The VOF model depends on both fluids accounting for large parts of the domain, while maintaining a relatively small contact area. For the double-body simulations, the movement of water cannot be modelled in such a way. Instead, the velocity is defined at the inlet boundary, whereas at the outlet, a pressure of $0 \mathrm{~Pa}$ is preserved.

The segregated flow model is used to solve the equations of state in an uncoupled manner. In all simulations, the convective terms are solved via a second order scheme, while the overall solution is obtained using a SIMPLE algorithm. The dynamic trim and sinkage of the ship is captured using a Dynamic Fluid-Body Interaction (DFBI) model, where only heave and pitch modes of motion are allowed.

\subsection{Time step selection}

The Courant-Friedreichs-Lewy ( $C F L)$ number is sometimes used as a condition to assess the convergence of simulated flows. It expresses the idea that if a flow is moving across a discrete special grid, we must choose a suitable time step $\Delta t$ and spacing $\Delta x$ to guarantee that the properties of the fluid (velocity, pressure) are solved for at each grid point. In such a case, $C F L \leq 1$. The ITTC (2011) recommends the use of $\Delta t=0.005 \sim 0.01 \mathrm{~L} / \mathrm{V}$, where $\mathrm{L}$ and $\mathrm{V}$ are the ship's length and speed, respectively. Tezdogan et al. (2016) and Terziev et al. (2018) demonstrated that the use of $\Delta t=0.0035 \mathrm{~L} / \mathrm{V}$ showed little error due to the discretisation of the temporal term in the Navier-Stokes equation, which was set as first order, and is therefore chosen for the present study as well.

\subsection{Mesh generation}

Mesh generation was performed using the automatic facilities of Star-CCM+, which allows the user to make use of several operations. The trimmed cell mesher is used to fabricate predominantly hexahedral cells. The alternative, using tetrahedral cells, has been shown to 
deliver unreliable results by Jones and Clarke (2010). The near-wall cells were generated using the prism layer mesher, which is used to fabricate orthogonal cells near the hull surface. Star$\mathrm{CCM}+$ automatically places these cells using a geometric progression to determine their dimensions. The prism layer thickness is set to equal the approximate value of the turbulent boundary layer thickness, derived by the 1/7 power law, found in White (2006).
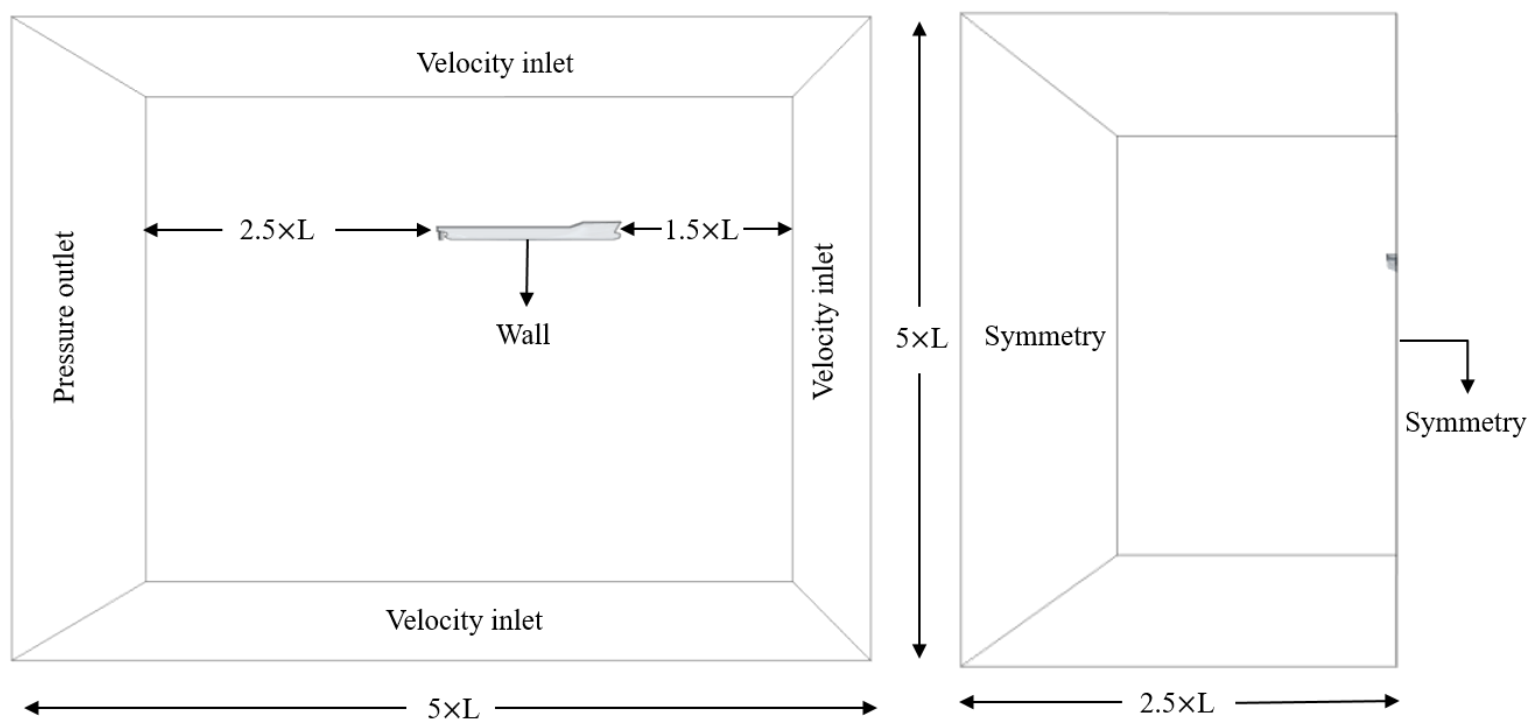

Figure 2. Domain boundary conditions and dimensions for the typical multiphase simulations

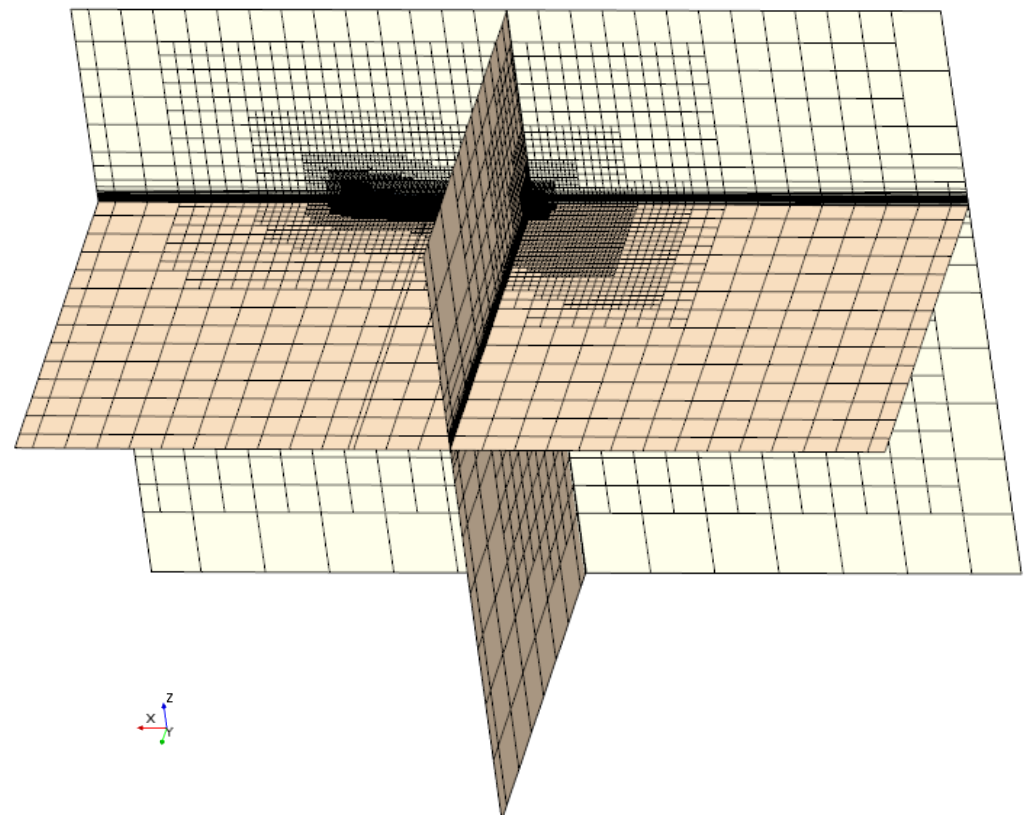

Figure 3. 3-D view of the generated mesh. Depicted: Full-scale

\subsection{Computational domain and boundaries}

According to Date and Turnock (1999), the boundary conditions of a CFD simulation play a critical role in both the accuracy and convergence of the solution. Their position as relative to 
the ship is equally important because, in rare cases, wave reflections may occur and that would invalidate the solution. To insure against this, the computational domain is constructed following the recommendations of the ITTC (2011). The resulting dimensions and boundary conditions are shown in Figure 2. A numerical beach model, the VOF damping length, is also applied to the outlet boundary equal to approximately $1.24 \mathrm{~L}$ in each scale.

Only half of the ship is simulated, thus, a symmetry plane is applied to all case-studies to alleviate the computational load and allow a larger number of cells to be used. The side boundary is set as symmetry because it does not allow changes in velocity or pressure across it to occur, i.e. it approximates /an infinitely wide deep sea. In any case, it is reasonable not to expect the Kelvin wake to reach the side boundary. The computational domain, shown in Figure 3, is scaled with the ship linearly to minimise numerical scale effects. The resulting three dimensional grid properties are shown in Table 2. Here, the cell count for the translated double body simulation in $\lambda=75$ have been highlighted to indicate their use in the viscous scaling procedure.

Table 2. Number of cells in each scale

\begin{tabular}{|l|l|r|r|r|r|}
\hline Scale & 1 & 31.599 & 52.667 & 75 \\
\hline \multirow{2}{*}{\begin{tabular}{c} 
Number of $\begin{array}{c}\text { cells } \\
\text { celly }\end{array}$ \\
\cline { 2 - 6 }
\end{tabular}} & Multiphase & $20,554,263$ & $12,343,685$ & $5,832,169$ & $3,338,447$ \\
\cline { 2 - 6 } & Double body: level & $5,166,585$ & $3,750,965$ & $2,703,735$ & $1,615,244$ \\
\cline { 2 - 6 } & Double body: translated & $5,532,073$ & $3,491,712$ & $2,739,160$ & $\mathbf{1 , 6 3 2 , 9 3 1}$ \\
\hline
\end{tabular}

\section{5 . Time-history of the numerical solution}

Calm water ship resistance is a steady state-problem. In other words, the solution is not affected regardless of how long the computation is performed for. However, in CFD, the ship experiences a well-known shock at the beginning of the simulation (Mucha, 2017). This can be mitigated by hydrostatic balancing (also referred to as 'equilibrium'), but is not implemented here to avoid contaminating the solution with deficiencies of numerical algorithms. According to Siemens (2018), the equilibrium option is a purely mathematical procedure that has no basis on physical rigid body motion. The alternative offered by the RANS solver consists of 'free motion', where the body is translated and rotated as a result of the forces acting on it at each time step, and is implemented here.

To reduce the shock effect, in this work, the ship is constrained in all directions for the first 5 seconds of the simulations. In Figure 4, the time-history is illustrated for the three components of resistance for $\lambda=31.599$. A ramp time of 10 seconds is also adopted, which gradually applies the forces on the hull to help reduce oscillatory motions. The combined effect of these two settings can be seen in Figure 4.

Transient effects in CFD have a potential to invalidate the results, which is why, as explained in Section 5.4, the domain boundaries must also be placed suitably. Figure 4 also demonstrates that the placement of the boundaries in the computational domain was successful, as well as the adequate decay of transient solution characteristics. 


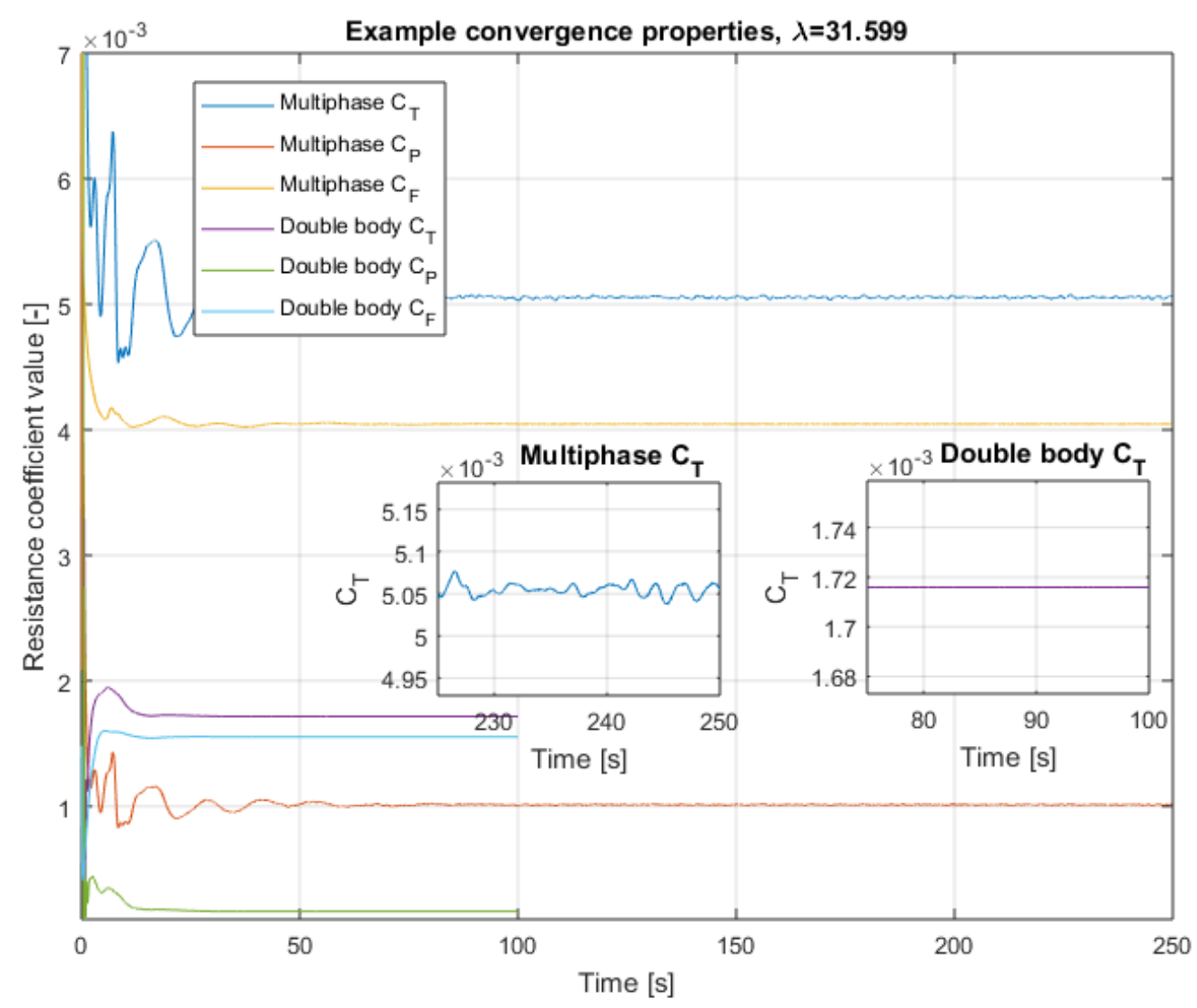

Figure 4. Example time-history of resistance and sinkage for case $\lambda=31.599$

To evaluate the iterative errors, the procedure of Roy and Blottner (2006) was used on the total resistance coefficients in multiphase and double body regimes. The analysis showed an absolute error of approximately $5.504 \times 10^{-4} \%$ and $2.112 \times 10^{-6} \%$ for multiphase and double body $\mathrm{C}_{\mathrm{T}}$ values, respectively, which was representative of other cases as well. These are used to justify the use of the numerical verification procedure, which assumes that iterative errors must be at least two orders of magnitude smaller than discretisation errors. In any case, all final values reported in this work are averaged over the last 25 seconds to ensure the final value is affected as little as possible by the iterative error.

Convergence properties can also be judged based on residuals. The residual of a numerical scheme can be broadly thought of as the (usually scaled) difference between the iteratively approximated solution and the perfect conservation of mass and momentum (ITTC, 2014). Typically, these are required to reduce by several orders of magnitude for the simulation result to be accepted. However, this is strictly dependent on how close the initial state of the simulation is to satisfying perfectly the discretised form of the governing equations (Siemens, 2018). This true is because if the initial state of the simulation is very close to satisfying the laws of conservation perfectly, the residuals will not reduce at all (Siemens, 2018). In other words, residual time-histories should not be used on their own to assess for convergence, although they are a powerful tool in any numerical analysis problem. Furthermore, the observed reduction in residual values is highly case-specific: a large reduction can still lead to a high validation error. 
In the present study, the double body residuals were found to reduce quickly by about five orders of magnitude (to $10^{-5} \sim 10^{-6}$ ) within approximately the first 4000 iterations (the ITTC's (2011) recommendation is a reduction of three orders of magnitude). This is a highly attractive feature of this type of set-up. It is also the reason why ship CFD simulations were performed in double body mode in the early days of the field, as discussed in Section 2. In the case of multiphase simulations, all residuals decreased by two orders of magnitude within the first 8000 iterations (considerably later than in the double body case). Reducing the magnitude of residuals further proved difficult. A representative case for the residual behaviour in both multiphase and double body modes is shown in Figure $5(\lambda=31.599)$.
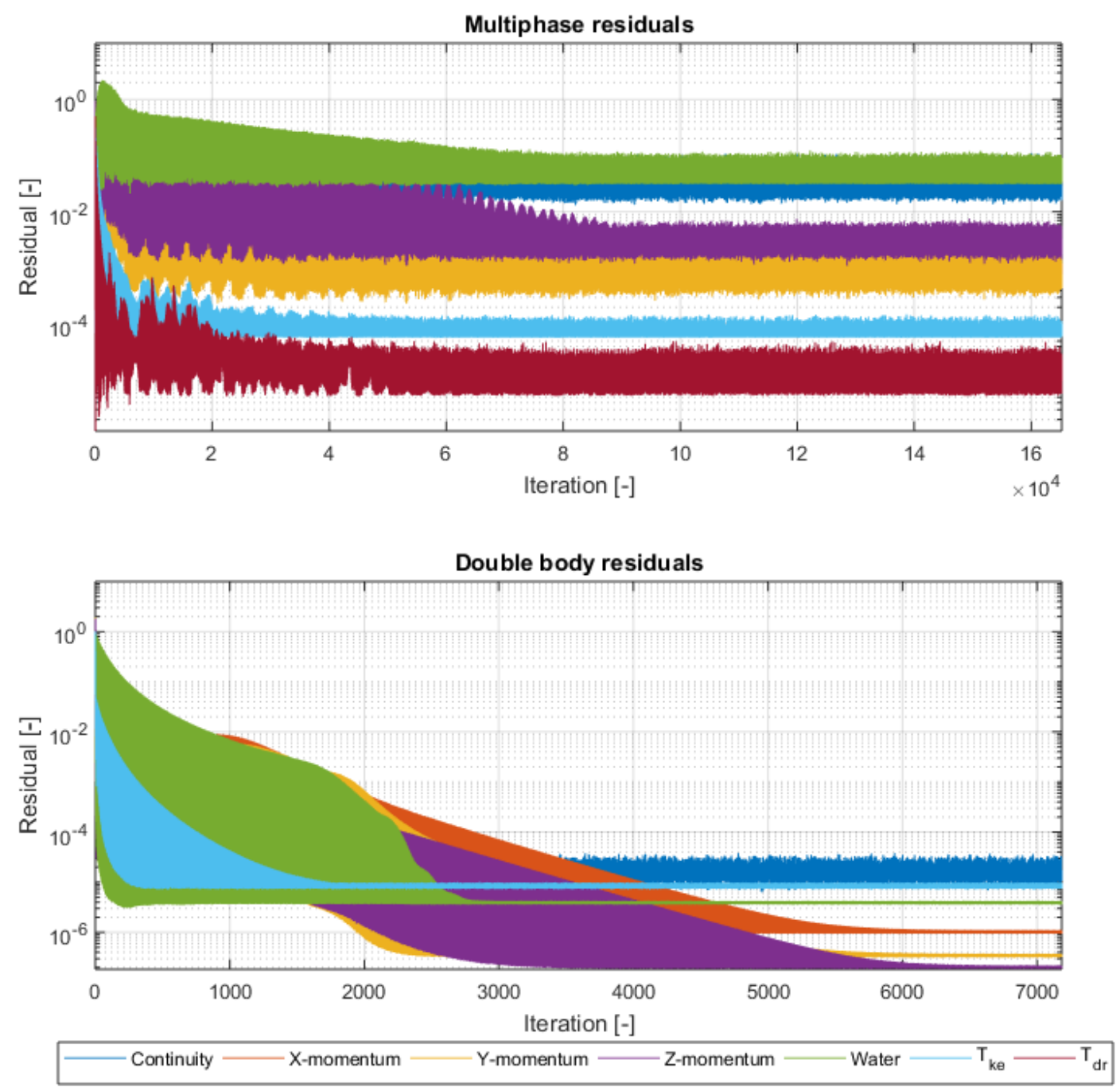

Figure 5. Residual time-history. Depicted: $\lambda=31.599$

In all cases, following the end of the transient oscillatory motion, residuals did not exhibit signs of reducing further. This is because the flow had fully developed at this stage. This is not problematic per se, because ship CFD - especially towed, calm water predictions - are not characterised by large ship motions or deformations of the free surface. Thus, while it is desirable to achieve a magnitude of the residuals that is as low as possible, a small reduction does not imply a 'bad' solution by itself.

According to ITTC (2014), even if the recommended three order of magnitude residual reduction cannot be achieved, integral values can be used to assess convergence of the solution, 
in particular, forces and moments acting on the hull (this is primarily in view of the complexity associated with the numerical simulation of ship flows). This was done earlier in this section in the case of iterative errors in resistance for $\lambda=31.599$. The following section presents the numerical verification study, which expands on the expected uncertainties due to spatial and temporal discretisation.

\subsection{Verification study}

It is inevitable to induce errors when temporally or spatially discretising the Navier-Stokes equations. Since we cannot model continuously the governing equations, we assume that errors decay rapidly as we decrease $\Delta t$ and $\Delta x$. In other words, the continuous equations should match our discretised versions as $\Delta t, \Delta x \rightarrow 0$.

The current method of estimating uncertainty in CFD simulations is based on expanding the error as a power series with integer powers of $\Delta t$ or $\Delta x$ (Xing and Stern, 2010), introduced by Richardson (1911). We begin by defining the four types of conditions which govern whether a solution is convergent or divergent as $\Delta t$ and $\Delta x$ are refined:

1. Monotonic convergence: $0<R_{k}<1$

2. Oscillatory convergence: $R_{k}<0 ;\left|R_{k}\right|<1$

3. Monotonic divergence: $R_{k}>1$

4. Oscillatory divergence: $R_{k}<0 ;\left|R_{k}\right|>1$

For conditions 3 and 4 , neither error nor uncertainty can be estimated. Here, $R_{k}$ is the convergence ratio, defined in Eq. (5):

$R_{k}=\varepsilon_{\kappa 21} / \varepsilon_{\kappa 32}$

where $\varepsilon_{k 21}$ is the difference between the medium $\left(\varphi_{k 1}\right)$ and fine $\left(\varphi_{k 2}\right)$ solutions, while $\varepsilon_{k 32}$ is the difference between the coarse $\left(\varphi_{k 3}\right)$ and medium $\left(\varphi_{k 2}\right)$ solutions. These $\left(\varphi_{k 2,3}\right)$ are obtained by systematically coarsening (by using the refinement ratio $r_{k}=\sqrt{2}$, recommended by the ITTC, (2008)) the $\mathrm{k}^{\text {th }}$ input parameter (Stern et al., 2006). In other words, the base size is multiplied by $\sqrt{2}$ while maintaining the smallest time step. The resulting cell counts are 1,674,346 and 880,876 for the medium and coarse mesh study for $\lambda=75$, respectively. The same procedure is applied to the time step, which is lessened by the same factor on the finest grid to isolate errors due to changes in temporal discretisation.

Table 3. Grid convergence for trim and total resistance coefficient

\begin{tabular}{|l|l|l|}
\hline & $\begin{array}{l}\text { Trim at CoG (with monotonic } \\
\text { convergence) }\end{array}$ & $\begin{array}{l}C_{T} \text { (with monotonic } \\
\text { convergence) }\end{array}$ \\
\hline$r$ & $\sqrt{2}$ & $\sqrt{2}$ \\
\hline$\varphi_{1}$ & 0.1642 & $4.2908 \times 10^{-3}$ \\
\hline$\varphi_{2}$ & 0.1653 & $4.2794 \times 10^{-3}$ \\
\hline$\varphi_{3}$ & 0.1693 & $4.2454 \times 10^{-3}$ \\
\hline$R$ & 0.2963 & 0.3600 \\
\hline$p$ & 3.5102 & 2.9480 \\
\hline$\Phi_{\text {ext }}^{21}$ & 0.1637 & $4.2972 \times 10^{-3}$ \\
\hline$e_{a}^{21}(\%)$ & 0.6914 & 0.2673 \\
\hline
\end{tabular}




\begin{tabular}{|l|l|l|}
\hline$e_{\text {ext }}^{21}(\%)$ & 0.3010 & 0.1486 \\
\hline$G C I_{\text {fine }}^{21}(\%)$ & 0.3638 & 0.1879 \\
\hline
\end{tabular}

Table 4. Time step convergence for trim and total resistance coefficient

\begin{tabular}{|l|l|l|}
\hline & $\begin{array}{l}\text { Trim at CoG (with monotonic } \\
\text { convergence) }\end{array}$ & $\begin{array}{l}C_{T} \text { (with monotonic } \\
\text { convergence) }\end{array}$ \\
\hline$r$ & $\sqrt{2}$ & $\sqrt{2}$ \\
\hline$\varphi_{1}$ & 0.1642 & $4.2908 \times 10^{-3}$ \\
\hline$\varphi_{2}$ & 0.1612 & $4.3002 \times 10^{-3}$ \\
\hline$\varphi_{3}$ & 0.1566 & $4.3315 \times 10^{-3}$ \\
\hline$R$ & 0.6716 & 0.2983 \\
\hline$p$ & 1.1483 & 3.4904 \\
\hline$\varphi_{\text {ext }}^{21}$ & 0.1703 & $4.2868 \times 10^{-3}$ \\
\hline$e_{a}^{21}(\%)$ & 1.8436 & 0.2180 \\
\hline$e_{\text {ext }}^{21}(\%)$ & 3.6346 & 0.0927 \\
\hline$G C I_{\text {fine }}^{21}(\%)$ & 4.7147 & 0.1158 \\
\hline & & \\
\hline
\end{tabular}

Since we maintain $r_{k}$ constant, the order-of-accuracy $\left(p_{k}\right)$ takes the form of:

$p_{k}=\ln \left(\varepsilon_{k 32} / \varepsilon_{k 21}\right) / \ln \left(r_{k}\right)$

Thus, we arrive at the extrapolated value $\left(\varphi_{\text {ext }}^{21}\right)$, according to Celik et al. (2008):

$\varphi_{\text {ext }}^{21}=\left(r_{k}^{p} \times \varphi_{1}-\varphi_{2}\right) /\left(r_{k}^{p}-1\right)$

Next, the approximate relative error, defined in Eq. (8), and extrapolated relative error, defined in Eq. (5), can be estimated.

$e_{a}^{21}=\left|\left(\varphi_{1}-\varphi_{2}\right) / \varphi_{1}\right|$

$e_{\text {ext }}^{21}=\left|\left(\varphi_{\text {ext }}^{12}-\varphi_{1}\right) / \varphi_{\text {ext }}^{12}\right|$

Finally, the grid convergence index $(G C I)$ can be calculated, shown in Eq. (10). This marks the end of our error estimation, mentioned in the introduction.

$G C I_{\text {fine }}^{21}=1.25 e_{a}^{21} /\left(r_{k}^{p}-1\right)$

Table 3 and Table 4 collectively show the numerical uncertainty is bound within acceptable limits. The adopted numerical set-up is more sensitive to changes due to the time step than due to cell number variations in the case of trim. The results suggest the opposite is true for the computed total resistance coefficients. The suspected cause for this is the turbulence model: even in the coarse mesh condition, we do not deviate from the $y^{+} \lesssim 1$ condition, where the $\kappa-\varepsilon$ turbulence model is known to perform well. It is not difficult to see that the $y^{+}$condition has been maintained because the number of wall-normal cells, as well as the thickness of the prism layer are independent of the base size, although the cell aspect ratio changes dramatically as the mesh is coarsened. On the other hand, trim is tied to the dynamic behaviour of the ship, where the lessening of $\Delta t$ has greater potential for impact. This, coupled with the uncertainty 
described previously regarding the effect turbulence modelling has on sinkage and trim is thought to be the root cause of the elevated GCI indices for trim.

\section{Results and discussion}

In this section, the obtained results are presented and compared against experimental values where possible. At the onset of this study, the parameters of interest were defined as the total resistance and its constituent components. Although prevalence will be given to these, running trim and sinkage are also considered.

\subsection{Error evaluation}

As alluded to in Section 2, experimental data were collected for three different scale factors. For $\lambda=75$, Shivachev et al. (2017) performed both tests, and CFD computations on the KCS without appendages. Simonsen et al. (2013) modelled the rudder, but not the propeller of the KCS in $\lambda=52.667$. Kim et al. (2001) performed experiments on the KCS without the rudder or propeller, and did not allow the ship to trim or sink. While the aim is to present results that are as realistic as possible, we cannot satisfy all three experimental set-ups. The decision made for the course of this paper is that the ship should be modelled with the rudder, since it has the potential to modify substantially the flow field near the stern. On the other hand, the propeller was omitted so as to avoid deviating too much from the experiments, the majority of which omitted the propeller. Finally, as explained in the previous section, the DFBI method is used to model sinkage and trim.

Table 5 shows the numerical and experimental total resistance coefficients. The error in $\lambda=31.599$ is based on the results of Kim et al. (2001). In all model scales, the error is bounded within the acceptable limit referred to in Section 2 (3\% deviation). An easily observed trend is that $\mathrm{C}_{\mathrm{T}}$ values are always over predicted, albeit slightly, by the adopted numerical set-up.

In the cases of sinkage and trim, the numerical calculations show a greater scatter. In $\lambda=75$, the trim was predicted within $1.3 \%$ of the experimental value (Table 6), which the present CFD set-up suggests remain largely unchanged as the ship is scaled. However, the experimental results show a greater trim in $\lambda=52.667$. The opposite seems to be suggested by the limited sample points for sinkage, which has been non-dimensionalised by ship length, shown in Table 7. Here, our results predict a reduction in sinkage with scale. Despite the aforementioned errors in trim and sinkage, our results suggest the principle of dimensional similarity holds to a greater degree than experiments do.

The errors reported could stem from a variety of sources. In model-scale experiments, turbulence stimulators are mounted near the bow of the ship. Thus, the numerical and experimental flows around the hull in each scale would have exhibited different turbulence characteristics. Furthermore, some variability is expected in the approach to turbulence stimulators between testing facilities. While their effect cannot be accounted for in sinkage and trim, the induced parasitic drag is subtracted. As reported in Larsson et al. (2014), turbulence modelling has a pronounced effect on sinkage, and we could, therefore, speculate that it could also have a similar effect on the trim. Factoring in the small uncertainty reported in each experimental study, it can be said that the resistance values have been predicted very well.

Although we established an acceptable level of error in all model-scale case-studies examined, it would be wrong to generalise this to full-scale. Indeed, without full-scale measurements one 
should be weary of making such a claim. The choice of the adopting the KCS provided us with the possibility of verifying the numerical set-up at each model-scale $\lambda$. However, it also prohibits us from attempting to carry this forward to full-scale since no real, full-scale equivalent of the KCS exists. Therefore, the full-scale wave resistance coefficients and form factors for the highest Reynolds number should be considered as an estimation rather than a concrete prediction. Furthermore, it is not practical to achieve $y^{+} \lesssim 1$ in full-scale due to the prohibitively large number of cells doing so would entail. Hence, the numerical set-up, where we can confidently claim that our results are accurate, strictly speaking, is not identical to the implemented full-scale set-up. Keeping this in mind, we have sufficient grounds and indeed verifiable data samples in model-scale to justify every conclusion drawn in the following subsections.

Table 5. Numerical and experimental total resistance coefficients, $F r=0.26$

\begin{tabular}{|c|c|c|c|c|c|c|}
\hline Method or source & $\begin{array}{l}\text { Scale } \\
(\lambda)\end{array}$ & $R e$ & $\begin{array}{l}\text { Software } \\
\text { package }\end{array}$ & $\begin{array}{l}\text { Numerica } \\
1\end{array}$ & $\begin{array}{l}\text { Experimen } \\
\text { tal }\end{array}$ & $\begin{array}{l}\text { Error } \\
(\%)\end{array}$ \\
\hline \multirow{3}{*}{$\begin{array}{l}\text { Shivachev et al. (2017), } \\
\text { no appendages }\end{array}$} & \multirow{4}{*}{75} & \multirow{4}{*}{$4.909 \times 10^{6}$} & \multirow{4}{*}{$\begin{array}{l}\text { Star- } \\
\text { CCM+ }\end{array}$} & $4.32 \times 10^{-3}$ & \multirow{4}{*}{$4.41 \times 10^{-3}$} & 2.041 \\
\hline & & & & $4.3 \times 10^{-3}$ & & 2.494 \\
\hline & & & & $4.23 \times 10^{-3}$ & & 4.023 \\
\hline $\begin{array}{l}\text { The current CFD: } \\
\text { multiphase }\end{array}$ & & & & $\begin{array}{l}4.291 \times 10^{-} \\
3\end{array}$ & & 2.703 \\
\hline \multirow[t]{2}{*}{ Simonsen et al. (2013) } & \multirow{3}{*}{$\begin{array}{l}52.66 \\
7\end{array}$} & \multirow{3}{*}{$8.342 \times 10^{6}$} & $\begin{array}{l}\text { CFDSHIP } \\
\text {-IOWA }\end{array}$ & $4.07 \times 10^{-3}$ & \multirow{3}{*}{$4.31 \times 10^{-3}$} & 5.568 \\
\hline & & & \multirow{5}{*}{$\begin{array}{l}\text { Star- } \\
\text { CCM+ }\end{array}$} & $4.42 \times 10^{-3}$ & & -2.552 \\
\hline $\begin{array}{l}\text { The current CFD: } \\
\text { multiphase }\end{array}$ & & & & $\begin{array}{l}4.232 \times 10^{-} \\
3\end{array}$ & & 1.818 \\
\hline $\begin{array}{l}\text { The current CFD: } \\
\text { multiphase }\end{array}$ & $\begin{array}{l}31.59 \\
9\end{array}$ & $1.794 \times 10^{7}$ & & $3.51 \times 10^{-3}$ & $3.557 \times 10^{-3}$ & 1.312 \\
\hline Tezdogan et al. (2015) & \multirow{2}{*}{1} & \multirow{2}{*}{$3.188 \times 10^{9}$} & & $2.295 \times 10^{-}$ & - & - \\
\hline $\begin{array}{l}\text { The current CFD: } \\
\text { multiphase }\end{array}$ & & & & $\begin{array}{l}2.294 \times 10^{-} \\
3\end{array}$ & - & - \\
\hline
\end{tabular}

Table 6. Numerical and experimental trim, $F r=0.26$

\begin{tabular}{|c|c|c|c|c|c|c|}
\hline Method or source & $\begin{array}{l}\text { Scale } \\
(\lambda)\end{array}$ & $\operatorname{Re}$ & $\begin{array}{l}\text { Software } \\
\text { package }\end{array}$ & $\begin{array}{l}\text { Numerical } \\
\text { (deg) }\end{array}$ & $\begin{array}{l}\text { Experimen } \\
\text { tal (deg) }\end{array}$ & $\begin{array}{l}\text { Error } \\
(\%)\end{array}$ \\
\hline \multirow{3}{*}{$\begin{array}{l}\text { Shivachev et al. (2017), } \\
\text { no appendages }\end{array}$} & \multirow{4}{*}{75} & \multirow{4}{*}{$4.909 \times 10^{6}$} & \multirow{4}{*}{$\begin{array}{l}\text { Star- } \\
\text { CCM+ }\end{array}$} & 0.198 & \multirow{4}{*}{0.162} & -22.222 \\
\hline & & & & 0.198 & & -22.222 \\
\hline & & & & 0.195 & & -20.370 \\
\hline $\begin{array}{l}\text { The current CFD: } \\
\text { multiphase }\end{array}$ & & & & 0.164 & & -1.330 \\
\hline Simonsen et al. (2013) & \multirow{3}{*}{$\begin{array}{l}52.66 \\
7\end{array}$} & \multirow{3}{*}{$8.342 \times 10^{6}$} & $\begin{array}{l}\text { CFDSHIP } \\
\text {-IOWA }\end{array}$ & 0.178 & \multirow{3}{*}{0.185} & 3.940 \\
\hline Simonsen et al. (2013) & & & \multirow{4}{*}{$\begin{array}{l}\text { Star- } \\
\text { CCM+ }\end{array}$} & 0.18 & & 2.860 \\
\hline $\begin{array}{l}\text { The current CFD: } \\
\text { multiphase }\end{array}$ & & & & 0.165 & & 10.708 \\
\hline $\begin{array}{l}\text { The current CFD: } \\
\text { multiphase }\end{array}$ & $\begin{array}{l}31.59 \\
9\end{array}$ & $1.794 \times 10^{7}$ & & 0.163 & - & - \\
\hline $\begin{array}{l}\text { The current CFD: } \\
\text { multiphase }\end{array}$ & 1 & $3.188 \times 10^{9}$ & & 0.153 & - & - \\
\hline
\end{tabular}


Table 7. Numerical and experimental sinkage/length, $F r=0.26$

\begin{tabular}{|c|c|c|c|c|c|c|}
\hline $\begin{array}{l}\text { Method or } \\
\text { source }\end{array}$ & Scale $(\lambda)$ & $\operatorname{Re}$ & $\begin{array}{l}\text { Software } \\
\text { package }\end{array}$ & Numerical & Experimental & $\begin{array}{l}\text { Error } \\
(\%)\end{array}$ \\
\hline \multirow{3}{*}{$\begin{array}{l}\text { Shivachev et } \\
\text { al. (2017), no } \\
\text { appendages }\end{array}$} & \multirow{4}{*}{75} & \multirow{4}{*}{$4.909 \times 10^{6}$} & \multirow{4}{*}{ Star-CCM+ } & $-1.957 \times 10^{-3}$ & \multirow{4}{*}{$-2.283 \times 10^{-3}$} & 14.286 \\
\hline & & & & $-1.950 \times 10^{-3}$ & & 14.571 \\
\hline & & & & $-1.924 \times 10^{-3}$ & & 15.714 \\
\hline $\begin{array}{l}\text { The current } \\
\text { CFD: } \\
\text { multiphase }\end{array}$ & & & & $-1.890 \times 10^{-3}$ & & 17.218 \\
\hline $\begin{array}{l}\text { Simonsen et } \\
\text { al. (2013) }\end{array}$ & \multirow{3}{*}{52.667} & \multirow{3}{*}{$8.342 \times 10^{6}$} & $\begin{array}{l}\text { CFDSHIP- } \\
\text { IOWA }\end{array}$ & $-2 \times 10^{-3}$ & \multirow{3}{*}{$-2.100 \times 10^{-3}$} & 4.762 \\
\hline $\begin{array}{l}\text { Simonsen et } \\
\text { al. (2013) }\end{array}$ & & & \multirow{4}{*}{ Star-CCM+ } & $-2.706 \times 10^{-3}$ & & -9.524 \\
\hline $\begin{array}{l}\text { The current } \\
\text { CFD: } \\
\text { multiphase }\end{array}$ & & & & $-1.897 \times 10^{-3}$ & & -9.667 \\
\hline $\begin{array}{l}\text { The current } \\
\text { CFD: } \\
\text { multiphase }\end{array}$ & 31.599 & $1.794 \times 10^{7}$ & & $-1.907 \times 10^{-3}$ & - & - \\
\hline $\begin{array}{l}\text { The current } \\
\text { CFD: } \\
\text { multiphase }\end{array}$ & 1 & $3.188 \times 10^{9}$ & & $-1.902 \times 10^{-3}$ & - & - \\
\hline
\end{tabular}

\subsection{Resistance decomposition}

In this study, the form factor approach is adopted, because it contains one parameter more than the Froude's approach on which scale effects can be examined: the form factor itself. As explained in section 3, by making use of the double body approach, there is no free surface $\left(C_{W}=0\right)$ which modifies the form factor equation to yield $(1+k)=C_{T} / C_{F}$. In this form, $(1+k)$ can be calculated directly using CFD (under the double body assumption), whether scaled geometrically, or via a modification to the value of dynamic viscosity $(\mu)$.

An initial estimate of the form factor during the early design stage can be as valuable as a precise calculation down the line. Therefore, three empirical relations to predict $(1+k)$ have been adopted from Molland et al. (2017). Alongside these, the corrections of García-Gómez (2000) and Min and Kang (2010) are applied.

\subsubsection{Wave resistance}

While Reynolds number effects on the form factor are practically uncontested, scale effects on wave resistance are largely unexamined. Doctors et al. (2007) suggested a 'wave resistance form factor' $\left(1+k_{w}\right)$, but did not provide a recommendation regarding its value. Doctors (2007) and Lazauskas (2009) defined this as $\left|k_{w}\right|<1$, and $k_{w}<0$ : a fundamentally different concept from the 'traditional' form factor. Unfortunately, we do not have a sufficiently large dataset for the KCS to establish a value for $k_{w}$ using a regression procedure. Even if that were the case, many hull forms must be examined under the same criteria to achieve a meaningful estimation applicable in general. 


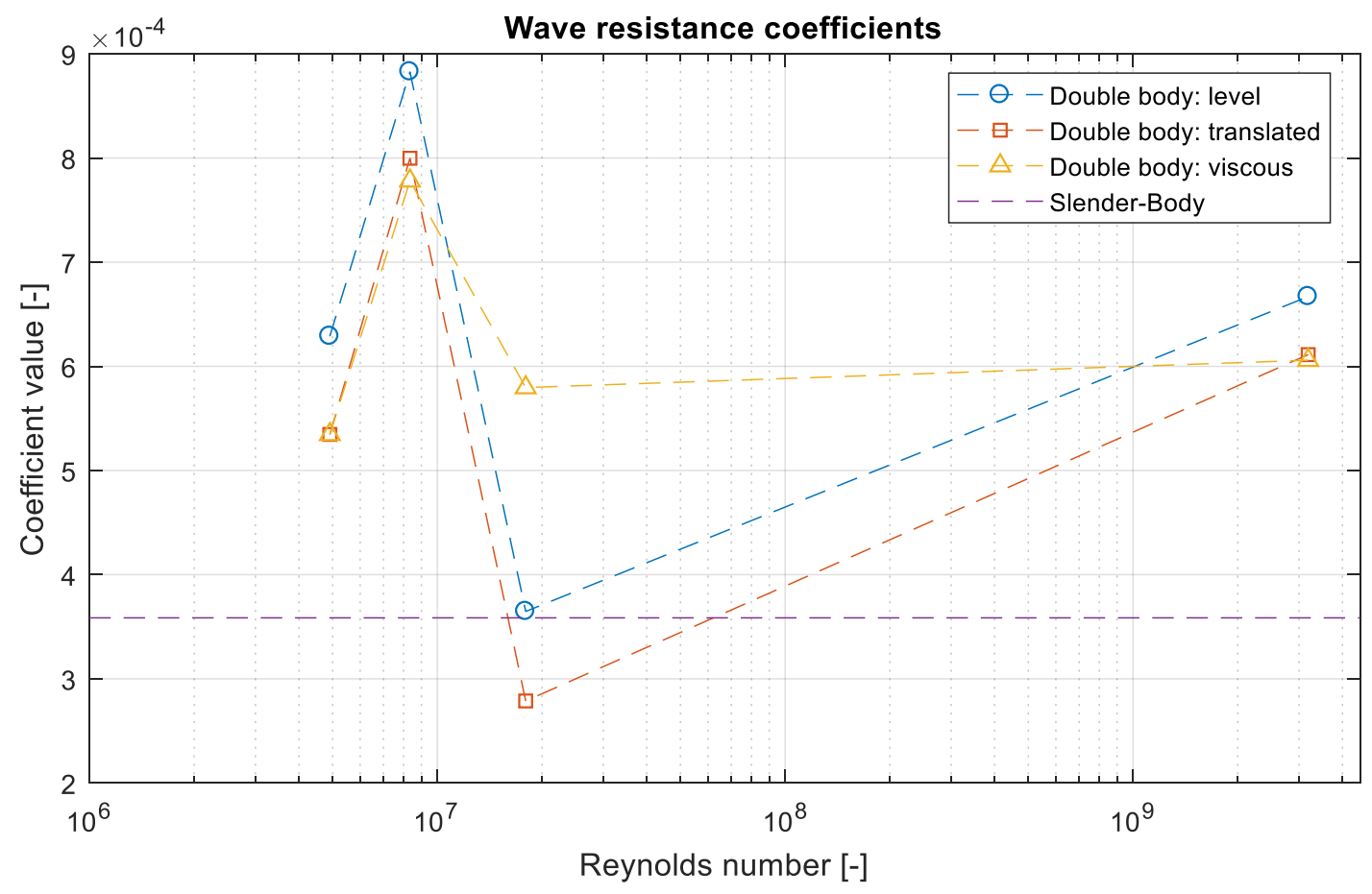

Figure 6. Wave resistance coefficients.

Figure 6 shows the predicted wave resistance coefficients for each scale according to the three different methods using CFD. Here, the Slender-body prediction, calculated using Bentley's Maxsurf Resistance software, is represented by a flat line because it is invariant with a change in Reynolds number. This figure presents the first indication that it may not be possible to achieve a smoothly varying curve for which general predictions can be made when large changes are applied to the $R e$. While all methods agree the general direction of the curve in every examined scale, there are disagreements between them at every examined $R e$. It is worth mentioning that the first point of the viscous scaled values, i.e. $\lambda=75$, is the same as the translated double body value. 

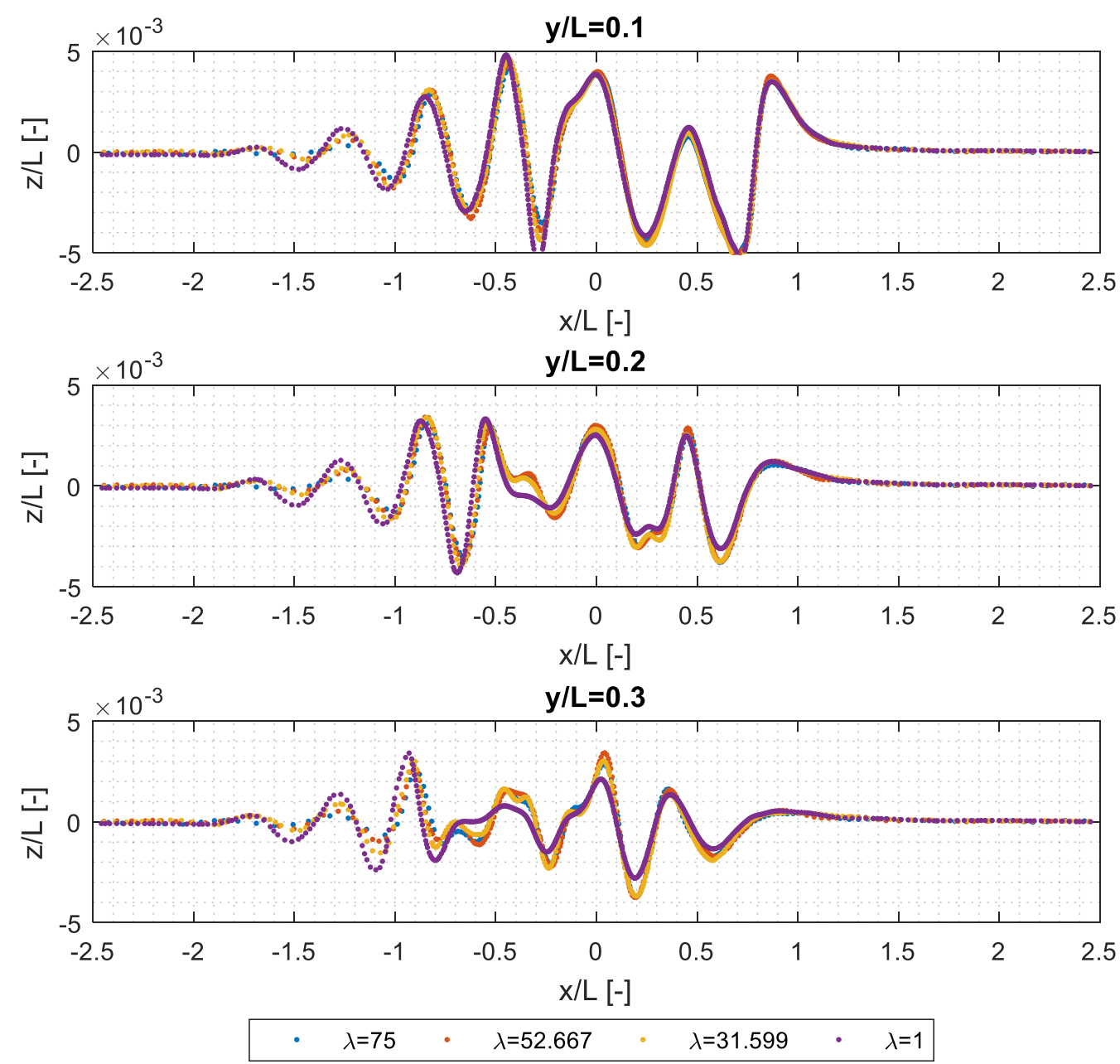

Figure 7. Wave cuts at $y / \mathrm{L}=0.1,0.2,0.3$ for all examined scale factors. The ship is located at $0<x / \mathrm{L}<1$, whereas the flow is in the negative $x$ direction.

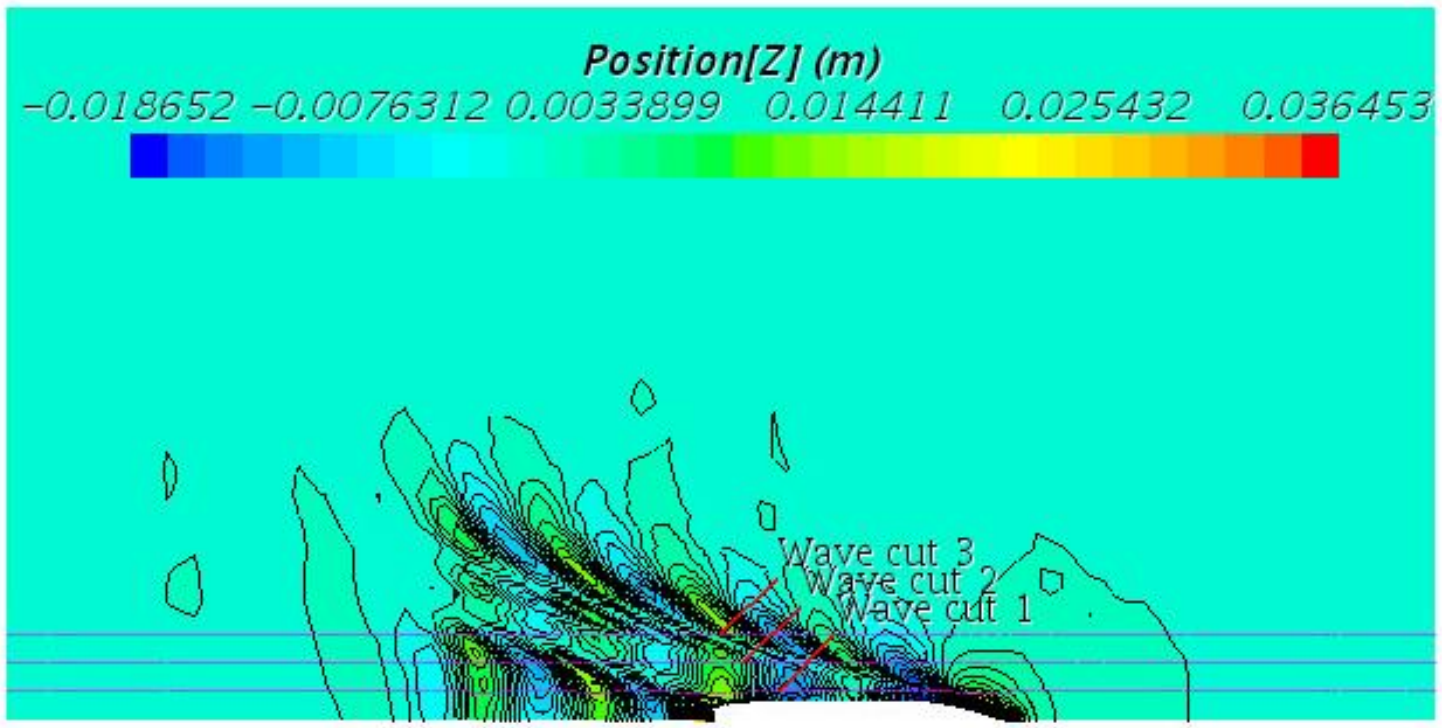

Figure 8. Relative locations of the wave cuts. Depicted: $\lambda=75$.

The change in wave resistance coefficient implies a geometrically non-similar wave pattern between scale factors. Here, we will not examine these, as identifying differences is difficult 
and subjective. Instead, to reveal differences, wave cuts are used, shown in Figure 7, at three different locations next to the ship. The relative positions of the wave cuts are shown in Figure 8 . In all $\lambda>1$ examined, the curves are sufficiently close to make them largely indistinguishable from each other. In full-scale, the differences become more pronounced. This is the suspected source of differences in wave resistance coefficient. It is interesting that changes are magnified as we move further away from the ship centreline, i.e. into the fully developed wake. In other words, changes to the wave field with scale require time to propagate some distance from the wave maker (the ship bow and stern) before differences become apparent. Therefore, the geometric scaling of the ship's bulbous bow, whose primary function is to modify the wave field is responsible for the observed differences in the wake. Indeed, the laminar portion of the boundary layer at the bulbous bow is appreciably stronger in model scale than that at full scale, inevitably creating discrepancies (Hochkirch and Mallol, 2000). On the other hand, the stern, being the second main source of wave-making, together with the interaction from the bow wave cause the dominant features observed between $-2.5<x / \mathrm{L}<0$ in Figure 7 . In reality, such differences are likely to be incorporated within the correlation allowance, used in extrapolation procedures.

Albeit small, errors in the predicted total resistance coefficient and their influence on the wave resistance should not be disregarded. Nevertheless, once decomposed, we expect these to be distributed, to some extent, among the constituent components of the total resistance. Thus, we could argue that the predicted error, spread over the frictional resistance, wave resistance, and form factor, is insignificant (in the 3D extrapolation case). Therefore, scale effects on wave resistance have been proven, conclusively rendering it a function of both the Reynolds number and Froude number.

In reality, the boundary layer's interaction with the wave field, and therefore wave resistance, is expected to resemble an iterative process, where the former modifies the latter and vice versa. Although this is largely ignored, several studies have documented such effects, for example Stern (1985). The effects of free surface flow effects on flat plates were examined in Longo et al. (1998), who reported changes in Reynolds stresses and mean velocity components. Marquardt (2009) stated that wave effects on the boundary layer are proportional to wave steepness and may influence the boundary layer up to half a wavelength (in the $-z$ direction). Suh et al. (2011) also identified deformation of vortical structures as a consequence of the presence of a phase interphase.

\subsubsection{Frictional resistance}

To quantify free surface effects on the frictional component of resistance, Figure 9 contains all CFD simulations performed in the study as well as the friction lines used for extrapolation. Although not frequently used in the literature, (in full-scale) the Telfer (1927) line passes just below the CFD predictions, while the Grigson (1999) method slightly overpredicts the multiphase result. The method proposed by Gadd (1967), on the other hand, passes through the predicted frictional resistance coefficients. The ITTC'57 line also provides a good approximation, underpredicting the values slightly.

The results of Figure 9 reveal that in the low $R e$ range (high $\lambda$ ), free surface effects are much more pronounced than in full-scale. There are several reasons for this. Primarily, the boundary layer affected by the free surface grows much more slowly than the skin friction of a fully submerged body. The latter increases with the wetted area $\left(\lambda^{2}\right)$, while the former changes 
approximately with the reciprocal of the $7^{\text {th }}$ root of the Reynolds number. Clearly, the boundary layer length will be equal to the length along the waterline, whereas the vertical distance at which it is disturbed can be estimated by the wavelength of the Kelvin wake. Methods to calculate this vary in complexity and robustness. While we will not attempt such a computation in this study, a piece of future work could seek to establish a relationship expressing the exact volume of the disturbed boundary layer by the generated waves. Simultaneously, the contribution of air resistance to the total friction was calculated as less than $0.3 \%$ of in all cases using the multiphase simulations.

Naturally, at low Froude numbers, the free surface is hardly disturbed (which also forms the basis for calculating the form factor), and double body approximations can provide good predictions (Landweber and Patel, 1979). Since the relative importance of free surface effects on the boundary layer decay rapidly with scale (similar to the displacement thickness), the aforementioned approximation can be used successfully at full-scale without significantly compromising the accuracy of the desired solution. That is, provided we are equipped with a tool capable of estimating the wave resistance separately with sufficient fidelity directly at fullscale.

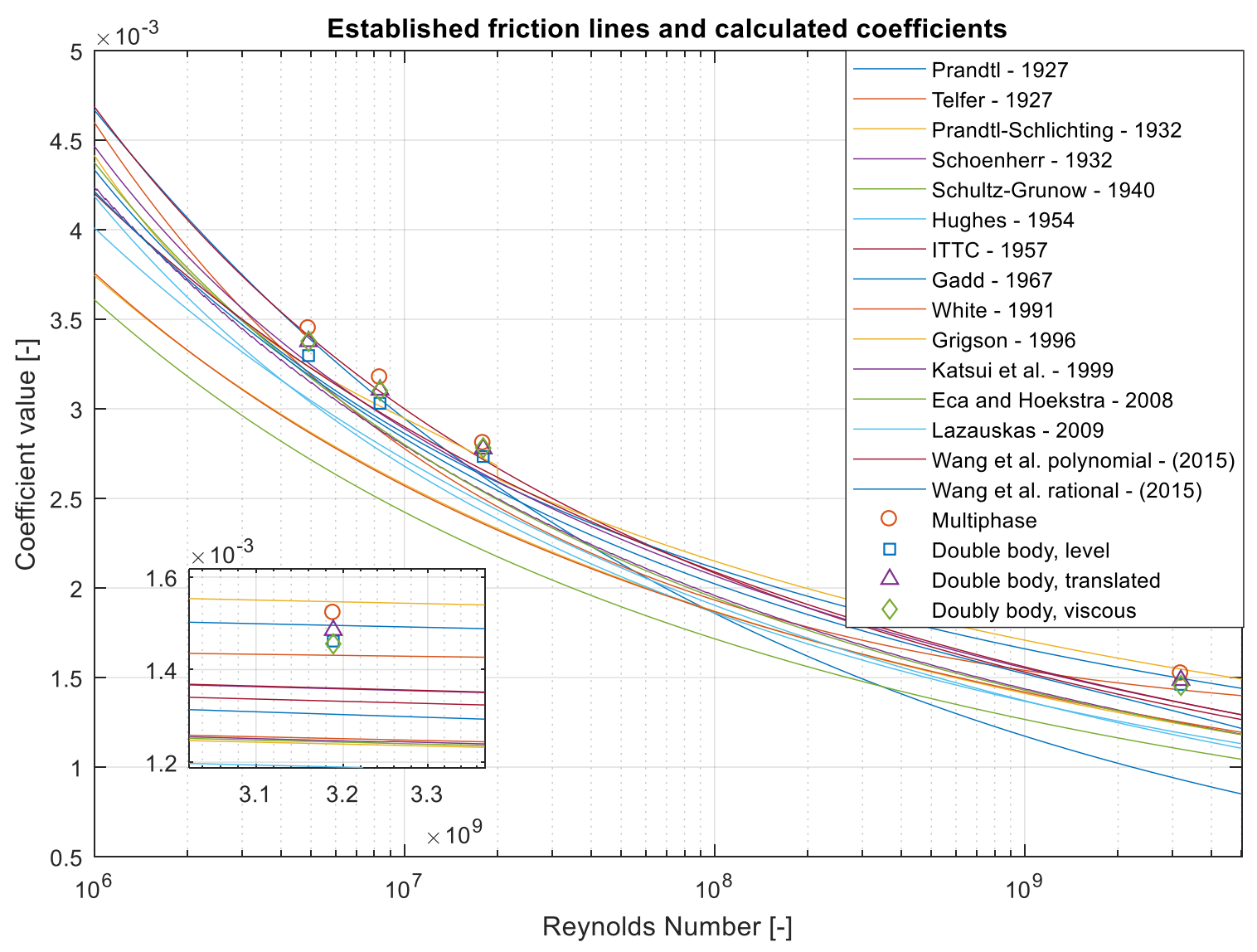

Figure 9. Frictional resistance coefficients

Mitchell's integral is used for many theoretical predictions of wave resistance, and forms the basis for the slender body method used in Figure 6. Its accuracy in full scale, however, is not as well documental as in model scale. Gotman (2002) asserted that if the ship has a convex 
transom, the wave resistance is over predicted. The opposite was suggested to be the case for concave transoms, while if the waterline is straight, or near straight, the values agree well with experiments in the range $F r<0.29$. Our results suggest that the above is only true in $\lambda=31.599$ (the KCS transom is convex). Thus, while confidence in numerical tools is largely lacking, it should also be questionable to use a single wave resistance coefficient for all scales.

It is a well-reported fact that the Schoenherr line matches almost exactly experimental values for the skin friction of plates (Bertram, 2012). The reason why we observe a deviation here between friction lines and CFD results was partially examined by Magionesi and Di Mascio (2016). They focused their attention on flows over ship bulbous bows, because, while a flat plate is characterised by a 0 pressure gradient (Peltier and Hambric, 2007), this is not the case for large parts of the ship's wetted area. Bulbous bows in particular exhibit pressure gradients, the boundary layer is three dimensional, and they are subject to free surface effects, which cannot be ignored (Ciappi and Magionesi, 2005). Ishihara et al. (2015) stated that turbulent boundary layers not only influence the large scale wake behind a structure, but also the location of separation. In the case of a ship, the boundary layer at the bulbous bow, being different from that of a flat plate, causes changes to cascade astern, and likely into the wake itself. The influence of separation is also of some concern in model-scale, while in full-scale it is practically irrelevant for low Froude numbers. Indeed, Figure 7 can be consulted in this respect near $x / \mathrm{L}=0$. Thus, differences in the flow around the ship between model and full-scale will be magnified as we increase the scale factor.

One final point to consider here is the Froude number. Having used a single $\operatorname{Fr}(0.26)$ in all simulations allowed us to isolate the effects of $R e$. Froude number effects on wave resistance are well documented. What is lacking in particular is its effect on the form factor. To resolve this, a larger scale study is required, featuring both numerical and experimental geosim analyses from a single institution to eliminate variability across testing facilities. This is left as a piece of future work.

\subsubsection{Form factor}

It is now appropriate to introduce the calculated form factors, shown in Figure 10, against Reynolds number. Surprisingly, the $(1+k)$ values do not exhibit a well-defined trend. Instead, some scatter is evident as the Reynolds number increases. A similar trend was discovered by Min and Kang, (2010), whose empirical correction depends solely on the $R e$. García-Gómez (2000) on the other hand, devised a formulae based on the scale factor. Both of these are shown in Figure 10 with the dashed, and dotted lines, respectively. What is most evident here is their change with scale factor or Reynolds number: both formulae predict an increase in $(1+k)$, whereas the CFD approach does not. Indeed, the error between the empirically corrected, translated double body form factor and multiphase $(1+k)$ value found is approximately $8.6 \%$. In the level double body case, this is even higher, reaching $10.9 \%$. It should be noted that the empirical form factors are placed for a $\lambda=31.599$. The abovementioned corrections are applied to them in order to demonstrate how they perform compared to the full-scale CFD results. 

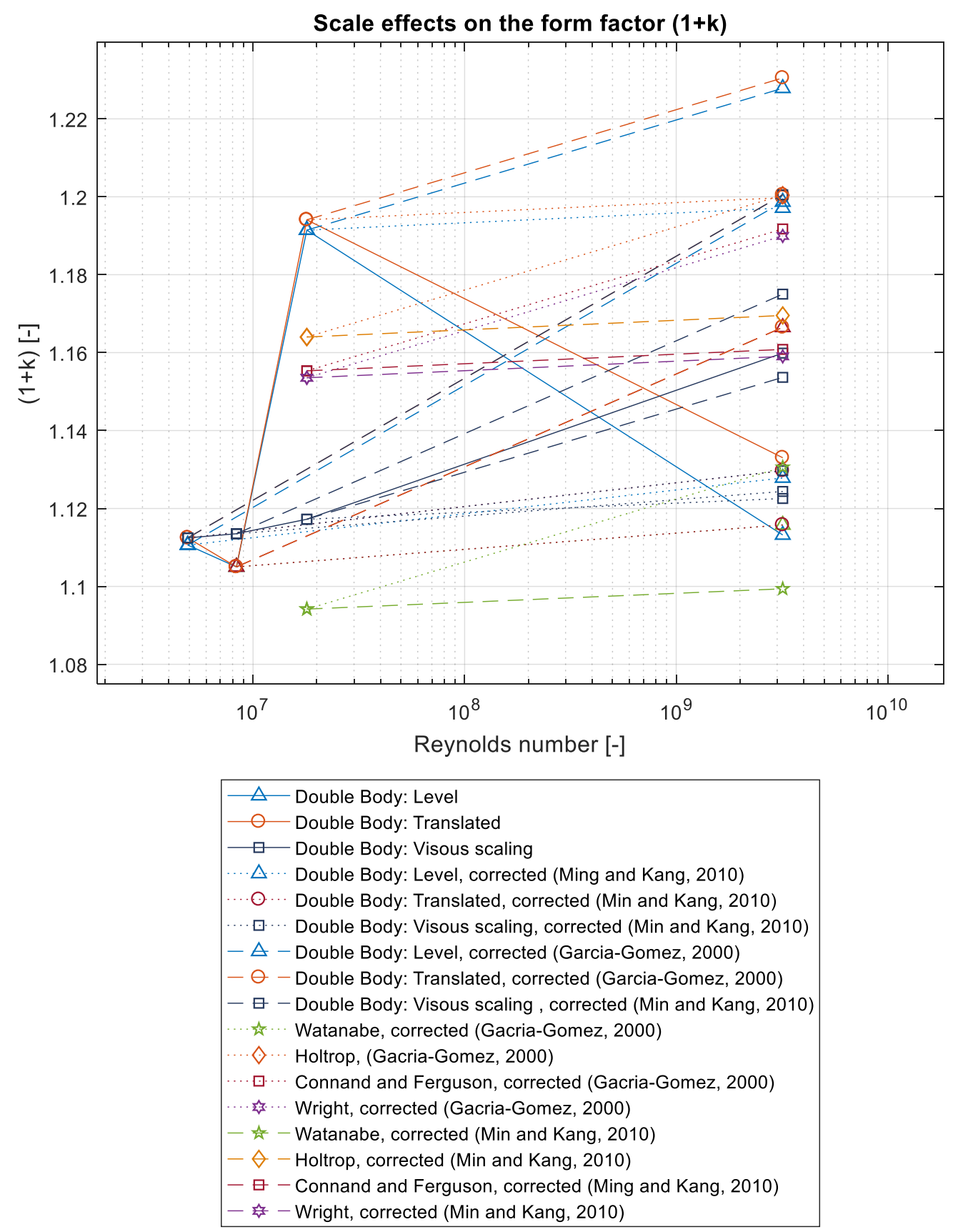

Figure 10. Calculated form factors

\subsubsection{Extrapolation to full-scale}

The presence of the scatter in values described previously implies there is a high degree of variability in the possible extrapolated value of the total resistance coefficient in full-scale. For example, two testing facilities using different scale factor to determine the wave resistance would find inconsistent $C_{T}$ values. To illustrate this, Figure 11 was compiled using all combinations of wave resistance coefficients (CFD and slender body), form factors (CFD and empirical, with and without the corrections of Min and Kang (2010) and García-Gómez (2000)), yielding 126 unique predictions for each friction line. Clearly, it is not possible to show the corresponding category for each point. Instead, the average of each friction line, global average, and the multiphase CFD prediction for $C_{T}$ are shown in Figure 11. Now, it is 
imperative to highlight the importance of reliable predictions for each component of the total resistance. For instance, although the Telfer (1927) line showed excellent predictions for the frictional resistance, its use may be questioned depending on the values chosen for the form factor and wave resistance. Of course, this is also the case for all other methods used. Figure 11 suggests a 'band' of possible values for each friction line exists. Therefore, a large degree of uncertainty can be expected depending on the adopted methodology to calculating each component of $C_{T}$.

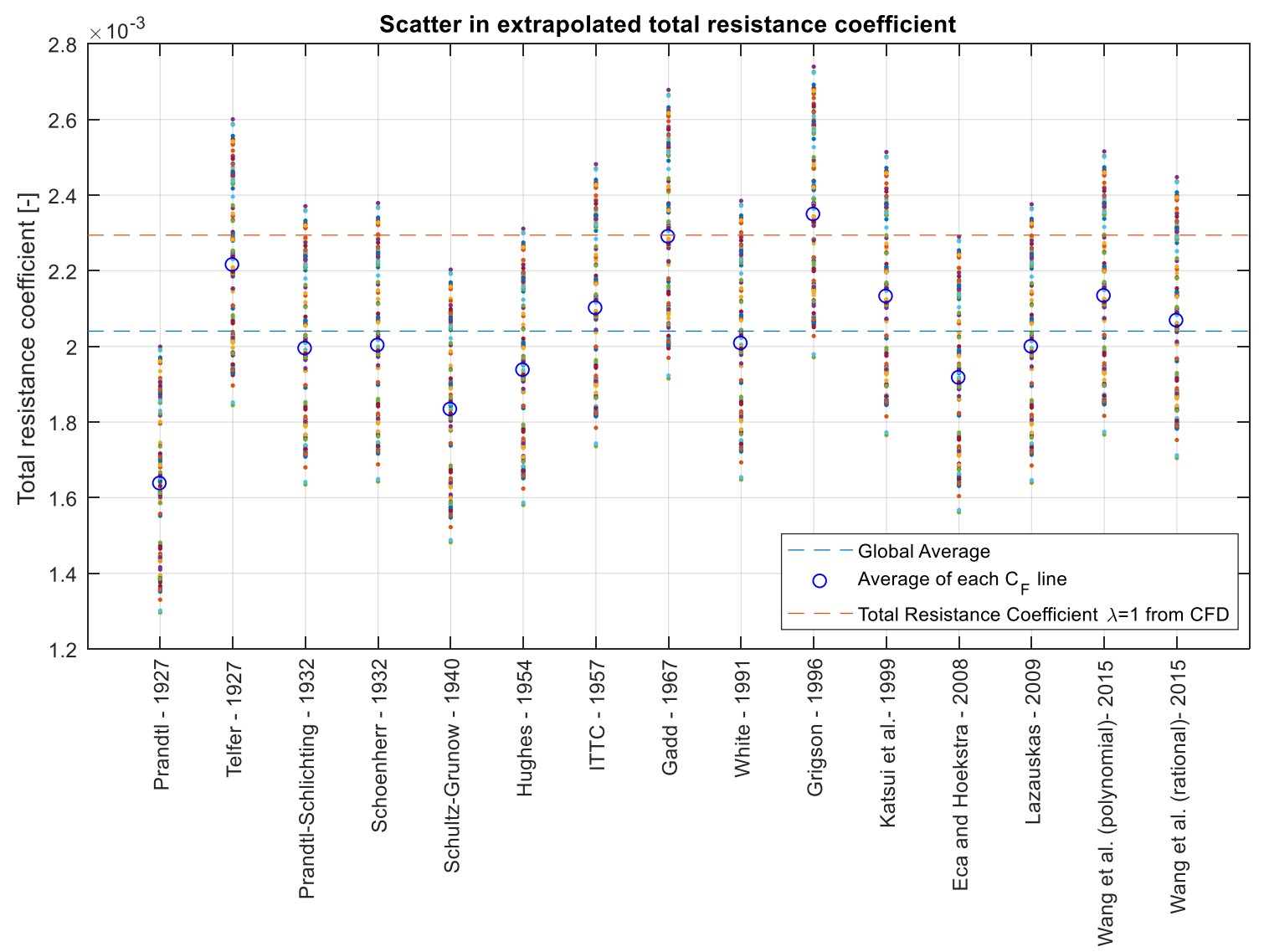

Figure 11. Extrapolated total resistance coefficient

Our assertion that a small error in the total resistance coefficient is decomposed into even smaller errors over each constituent component worked to our advantage earlier. However, if the process is reversed, the effect is magnified to yield a high degree of uncertainty. Thus, the importance of high fidelity methods cannot be overstated. One possible problem is that virtually all of the available literature treats these problems (the evaluation of the total's constituent components) separately. For example, one may determine a method to calculate the exact frictional resistance for a specific Reynolds number. Indeed, the available methods perform very well, as shown in this paper. However, if free surface effects are not accounted for in the extrapolation procedure from a Reynolds number in the region of $10^{6}$, to one near $5 \times 10^{9}$, the results will not resemble reality. This would influence all parameters present in the decomposition of the total resistance coefficient and would likely be amplified when carried to full scale. An analogous argument can be made for the estimation of wave resistance, although there uncertainty in its estimation due to the degree of complexity associated with ship wave making. 
A more fundamental problem arises from the ambiguity resulting from the amplification of errors discussed above: it becomes difficult to justify validating the estimation of each constituent component of the total resistance when calculated separately. Perhaps the best example in this context is the prediction of wave resistance by potential flow methods. These are typically validated by subtracting the viscous resistance $(1+k) C_{F}$ from the experimentally obtained total, for instance, Tuck and Lazauskas (2008). Now $C_{F}$ is usually obtained via one of the friction lines in Figure 9 (typically the ITTC57 line), while $(1+k)$ - experimentally using the procedure stated in Section 2. As demonstrated in this study, both of these are susceptible to scale effects and therefore contain a certain amount of error when carried to full-scale. Consequently, the use of wave resistance potential flow methods in extrapolation procedures should be approached with caution, not least because they fail to model scale effects. Referring to validation versus experiments, the problem is not confined to the use of methods based on Michell's (1898) integral. Instead, wave cut methods (Janson and Spinney, 2004) and panel methods (Newman, 1992), both of which are deemed reliable and robust, must suffer from the above issue. To circumvent this obstacle, wave probes can be used during tank testing (Kim et al., 2001; Townsin, 1971, 1968; Troesch and Beck, 1974). Using an experimental analogue to the wave cut method, the energy in the waves around a model ship can be calculated, removing the theoretician's reliance on friction lines or form factor estimations.

Alternatively, a recently emerging method is to capture high quality optical images of the free surface around the ship (Gomit et al., 2014). Applying this method, Caplier et al. (2016) estimated the energy contained in a ship's wake by using its spectrogram, defined as a heat map used to visualise the time-dependent height of the water surface in terms of a frequency spectrum (Pethiyagoda et al., 2018, 2017). Here, only half of the obstacle has been addressed. The remainder (scale effects) seems insurmountable with present methods, especially with the apparent scatter of $C_{W}$ observed in Figure 6.

The use of CFD methods undoubtedly increases our understanding of the underlying phenomena and their relative importance. However, there is still a fundamental source of uncertainty present in their use: the statistical modelling of turbulence, usually referred to as turbulence modelling. We have shown in this paper that it is the most probable source of errors in sinkage and trim, whose effect cannot be neglected. One could argue along the lines of Moore (1965) with regards to the availability of computational power, and claim that Direct Numerical Simulation (DNS) will solve our problems in this respect if we allow sufficient time to increase the available computational power. However, even today, the use of DNS is limited to a narrow range of Reynolds numbers, which is far from sufficient even for model-scale computations (Beck and Reed, 2001). Simultaneously, the field of wall function derivation is very active (Kiš and Herwig, 2012). Even if we choose to accept the use of turbulence modelling, Pereira et al. (2017) found that different models are best suited for hull resistance prediction and propeller dynamics. Then, in the words of Lamb (1932), turbulence remains the "chief outstanding difficulty of our subject" despite the immeasurable increase in computational power availability since.

\section{Conclusions and future work}

This study focused on scale effects on ship bare hull resistance. Several hypotheses were tested using a commercially available RANS solver. Emphasis was placed on challenging the widely used assumption of geometric similarity in ship wave patterns with scale, and thus a scale 
invariant wave resistance, which was shown to be untrue, confirming the results of Raven et al. (2008). Scale effects on all examined parameters were shown to be magnified with large changes in the Reynolds number. This was accomplished by maintaining the Froude number constant throughout all adopted case-studies $(F r=0.26)$.

We demonstrated that the relative importance of free surface effects of frictional resistance decay rapidly with an increase in Reynolds number, but can substantially influence extrapolated results if not properly accounted for. Several sources for this have been identified, including boundary layer thickness and flow separation. These are also the likely cause of nongeometrically similar wave patterns observed in this study.

It is hoped that the present work will create an interest in wave resistance changes with scale, a topic largely ignored in the study of ship resistance. A more scientific extrapolation procedure is required to replace the experience-based approach most facilities seem to have adopted. While the ITTC's procedure has been widely criticised for years, little progress has been made towards its improvement, largely stagnating new developments in this direction. The problems associated with scale effects do not necessarily come from the decomposition and extrapolation procedure itself, rather the assumptions imposed as part of it. Were these to be relaxed or reexamined with modern computational tools, progress could be achieved. For example, the form factor is not constant with scale. Instead, it depends on both the Reynolds number and Froude number.

An alternative path worth exploring is to perform all computations directly in full-scale. While the resources required to perform a full-scale computation seem to be limited, experience suggests that time improves computational availability. We could then argue that it is only a matter of time before it becomes commonplace to routinely perform full-scale CFD simulations. One of the main issues academia must seek to resolve is that of turbulence modelling, which is a very active field of research where strides of progress are being made.

Roughness and fouling are an area we did not explore in the present study as they would complicate matters significantly. Nevertheless, these should be examined in a similar fashion to determine the reliability of model-scale results. Building on previous research of Demirel et al. (2017, 2014), the recent work of Song et al. (2019) demonstrates the intricacies of the subject, which remain unexplored here.

From the onset of this study, in performing numerical simulations, our intention was to maintain the highest possible degree of similarity with the real-life physics of the problem. However, we tacitly omitted to incorporate propeller effects. The complex, non-uniform flow, generated by the presence of a rotating propeller is responsible for stark changes in the overall pressure and velocity fields near the ship's stern. While by ignoring such effects, we may have deviated from representing the overall problem, it is thought that isolating the bare hull resistance is a worthwhile endeavour. Indeed, to the best of our knowledge, the present study is the first to examine scale effects on the wave resistance and free surface effects on the frictional resistance using CFD.

\section{Acknowledgements}

Results were obtained using the ARCHIE-WeSt High Performance Computer (www.archiewest.ac.uk) based at the University of Strathclyde. The authors would like to thank Miss Dilyana Hristova for her help with the final proofreading. The work reported in this paper is 
drawn from the first author's $\mathrm{PhD}$ thesis. The first author gratefully acknowledges the scholarship provided by the Faculty of Engineering at the University of Strathclyde, which fully supports his $\mathrm{PhD}$. 


\section{References}

Beck, R.F., Reed, A.M., 2001. Modern Computational Methods for Ships in a Seaway. SNAME Trans. 109, 1-55.

Bertram, V., 2012. Resistance and Propulsion, Practical Ship Hydrodynamics. https://doi.org/10.1016/B978-0-08-097150-6.10003-X

Bugalski, T., 2007. An overview of the selected results of the European Union Project EFFORT. Arch. Civ. Mech. Eng. 7, 55-67. https://doi.org/10.1016/S16449665(12)60013-2

Caplier, C., Rousseaux, G., Calluaud, D., David, L., 2016. Energy distribution in shallow water ship wakes from a spectral analysis of the wave field. Phys. Fluids 28. https://doi.org/10.1063/1.4964923

Celik, I.B., Ghia, U., Roache, P.J., Freitas, C.., 2008. Procedure for Estimation and Reporting of Uncertainty Due to Discretization in CFD Applications. J. Fluids Eng. 130, 078001. https://doi.org/10.1115/1.2960953

Ciappi, E., Magionesi, F., 2005. Characteristics of the turbulent boundary layer pressure spectra for high-speed vessels. J. Fluids Struct. 21, 321-333. https://doi.org/10.1016/j.jfluidstructs.2005.07.006

Date, C.J., Turnock, S., 1999. A study into the techniques needed to accurately predict a skin friction using RANS solvers with validation against Froude's historical flat place experimental data, Ship science report No. 114.

Demirel, Y.K., Khorasanchi, M., Turan, O., Incecik, A., Schultz, M.P., 2014. A CFD model for the frictional resistance prediction of antifouling coatings. Ocean Eng. 89, 21-31. https://doi.org/10.1016/j.oceaneng.2014.07.017

Demirel, Y.K., Turan, O., Incecik, A., 2017. Predicting the effect of biofouling on ship resistance using CFD. Appl. Ocean Res. 62, 100-118. https://doi.org/10.1016/j.apor.2016.12.003

Doctors, L.J., 2007. A Numerical Study of the Resistance of Transom-Stern Monohulls. Sh. Technol. Res. 54, 134-144. https://doi.org/10.1179/str.2007.54.3.005

Doctors, L.J., Macfarlane, G.J., Young, R., 2007. A study of transom-stern ventilation. Int. Shipbuild. Prog. 54, 145-163.

Durbin, P.A., Pettersson Reif, B.A., 2011. Statistical theory and modelling for turbulent flow, Second Edi. ed. Wiley.

Duvigneau, R., Visonneau, M., Deng, G.B., 2003. On the role played by turbulence closures in hull shape optimization at model and full scale. J. Mar. Sci. Technol. 8, 11-25. https://doi.org/10.1007/s10773-003-0153-8

Eca, L., Hoekstra, M., 2008. The numerical friction line. J. Mar. Sci. Technol. 13, 328-345. https://doi.org/10.1007/s00773-008-0018-1

Eca, L., Hoekstra, M., 2001. Numerical Prediction of Scale Effects in Ship Stern Flows with Eddy-Viscosity Turbulence Models, in: Twenty-Second Symposium on Naval Hydrodynamics Office of Naval Research Bassin d'Essais Des CarenesNational Research Council. pp. 553-568. https://doi.org/10.17226/9771 
Eca, L., Saraiva, G., Vaz, G., Abreu, H., 2015. The Pros and Cons of Wall Functions. OMAE2015, St.Johns, Newfoundland, Canada 0-11. https://doi.org/10.1115/OMAE2015-41518

Froude, W., 1874. Report to the lords commissioners of the admiralty on experiments for the determination of the frictional resistance of water on a surface, under various conditions, performed at Chelston cross, under the authority of their lordships.

Gadd, G.E., 1967. A new turbulent friction formulation based on a reappraisal of Hughes' results. Trans. RINA 109, 109-511.

García-Gómez, A., 2000. On the form factor scale effect. Ocean Eng. 27, 97-109. https://doi.org/10.1016/S0029-8018(98)00042-0

Gomit, G., Rousseaux, G., Chatellier, L., Calluaud, D., David, L., 2014. Spectral analysis of ship waves in deep water from accurate measurements of the free surface elevation by optical methods. Phys. Fluids 26. https://doi.org/10.1063/1.4902415

Gotman, A., 2007. A history of ship resistance evaluation. J. Ocean Technol. 2, 74-96.

Gotman, A.S., 2002. Study Of Michell's Integral And Influence Of Viscosity And Ship Hull Form On Wave Resistance. Ocean. Eng. Int. 6, 74-115.

Grigson, C.W.B., 1999. A planar friction algorithm and its use in analysing hull resistance. Trans. RINA.

Guo, C., Zhang, Q., Shen, Y., 2015. A non-geometrically similar model for predicting the wake field of full-scale ships. J. Mar. Sci. Appl. 14, 225-233. https://doi.org/10.1007/s11804-015-1316-8

Haase, M., Zurcher, K., Davidson, G., Binns, J.R., Thomas, G., Bose, N., 2016. Novel CFDbased full-scale resistance prediction for large medium-speed catamarans. Ocean Eng. 111, 198-208. https://doi.org/10.1016/j.oceaneng.2015.10.018

Hirt, C.. W., Nichols, B.. D., 1981. Volume of fluid (VOF) method for the dynamics of free boundaries. J. Comput. Phys. 39, 201-225. https://doi.org/10.1016/00219991(81)90145-5

Hochkirch, K., Mallol, B., 2000. On the Importance of Full-Scale CFD Simulations for Ships. Numeca 85-95.

Hou, Y. hang, Li, Y. jia, Liang, X., 2019. Mixed aleatory/epistemic uncertainty analysis and optimization for minimum EEDI hull form design. Ocean Eng. 172, 308-315. https://doi.org/10.1016/j.oceaneng.2018.12.003

Hughes, G., 1954. Friction and form resistance in turbulent flow and a proposed formulation for use in model and ship correlation. Trans. Inst. Nav. Arch. 96.

IMO, 2011. Annex 19: Resolution MEPC.203(62).

Ishihara, T., Ogasawara, H., Hunt, J.C.R., 2015. Analysis of conditional statistics obtained near the turbulent/non-turbulent interface of turbulent boundary layers. J. Fluids Struct. 53, 50-57. https://doi.org/10.1016/j.jfluidstructs.2014.10.008

ITTC, 2017. Recommended Procedures 1978 ITTC Performance Prediction Method, 4th revision, 7.5 - 0203 - 01.4. 28th Int Towing Tank Conf. 
ITTC, 2014. ITTC - Recommended Procedures and Guidelines - Practical guidelines for ship CFD applications. 7.5-03-02-03 (Revision 01). ITTC - Recomm. Proced. Guidel. 19.

ITTC, 2011. Recommended Procedures and Guidelines: Practical Guidelines for Ship CFD. 26th Int. Towing Tank Conf.

ITTC, 2008. Uncertainty Analysis in CFD Verification and Validation Methodology and Procedures. 25th ITTC 2008, Resist. Comm. 12.

Janson, C.-E., Spinney, D., 2004. A Comparison of Four Wave Cut Analysis Methods for Wave Resistance Prediction. Sh. Technol. Res. 51, 173-184. https://doi.org/10.1179/str.2004.51.4.004

Jones, D.A., Clarke, D.B., 2010. Fluent Code Simulation of Flow around a Naval Hull: the DTMB 5415. Def. Sci. Technol. Organ. Victoria (Australia), Marit. platforms Div.

Katsui, T., Asai, H., Himeno, Y., Tahara, Y., 2005. The proposal of a new friction line, in: Fifth Osaka Colloquium on Advanced CFD Applications to Ship Flow and Hull Form Design, Osaka, Japan.

Kim, W.J., Van, S.H., Kim, D.H., 2001. Measurement of flows around modern commercial ship models. Exp. Fluids 31, 567-578. https://doi.org/10.1007/s003480100332

Kiš, P., Herwig, H., 2012. The near wall physics and wall functions for turbulent natural convection. Int. J. Heat Mass Transf. 55, 2625-2635. https://doi.org/10.1016/j.ijheatmasstransfer.2011.12.031

Kouh, J.S., Chen, Y.J., Chau, S.W., 2009. Numerical study on scale effect of form factor. Ocean Eng. 36, 403-413. https://doi.org/10.1016/j.oceaneng.2009.01.011

Lamb, H., 1932. Hydrodynamics. Cambridge Univ. Press 6th revise, 262-264. https://doi.org/10.1017/CBO9781107415324.004

Landweber, L., Patel, V.C., 1979. Ship Boundary Layers. Annu. Rev. Fluid Mech. 11, 173205. https://doi.org/10.1146/annurev.fl.11.010179.001133

Larsson, L., Stern, F., Visonneau, M., 2014. Numerical Ship Hydrodynamics: An assessment of the Gothenburg 2010 Workshop. Springer. https://doi.org/10.1007/978-94-007-71895

Lazauskas, L. V, 2009. Resistance, Wave-Making and Wave-Decay of Thin Ships, with Emphasis on the Effects of Viscosity.

Lee, Y.G., Ha, Y.J., Lee, S.H., Kim, S.H., 2018. A study on the estimation method of the form factor for a full-scale ship. Brodogradnja 69, 71-87.

https://doi.org/10.21278/brod69105

Longo, J., Huang, H.P., Stern, F., 1998. Solid/free-surface juncture boundary layer and wake. Exp. Fluids 25, 283-297. https://doi.org/10.1007/s003480050232

Magionesi, F., Di Mascio, A., 2016. Investigation and modelling of the turbulent wall pressure fluctuations on the bulbous bow of a ship. J. Fluids Struct. 67, 219-240. https://doi.org/10.1016/j.jfluidstructs.2016.09.008

Marquardt, M.W., 2009. Effects of waves and the free surface on a surface-piercing flat-plate turbulent boundary layer and wake. University of Iowa. 
Michell, J.H., 1898. The wave-resistance of a ship. London, Edinburgh, Dublin Philos. Mag. J. Sci. 45, 106-123.

Min, K.-S., Kang, S.-H., 2010. Study on the form factor and full-scale ship resistance. J. Mar. Sci. Technol. 15, 108-118. https://doi.org/10.1007/s00773-009-0077-y

Molland, A.F., Turnock, S.R., Hudson, D.A., 2017. Model-Ship Extrapolation, in: Ship Resistance and Propulsion: Practical Estimation of Ship Propulsive Power. Cambridge University Press, Cambridge, pp. 70-85. https://doi.org/10.1017/9781316494196.006

Moore, G.E., 1965. Cramming more components onto integrated circuits, in: Proceedings Of The IEEE. pp. 82-85. https://doi.org/10.1109/N-SSC.2006.4785860

Mucha, P., 2017. On Simulation-based Ship Maneuvering Prediction in Deep and Shallow Water.

Newman, J.N., 1992. Panel methods in marine hydrodynamics. 11th Australas. Fluid Mech. Conf.

Oh, K.J., Kang, S.H., 1992. Full scale Reynolds number effects for the viscous flow around the ship stern. Comput. Mech. 9, 85-94. https://doi.org/10.1007/BF00370064

Patel, V.C., Sarda, O.P., 1990. Mean-flow and turbulence measurements in the boundary layer and and wake of a ship double model. Exp. Fluids 8, 319-335. https://doi.org/https://doi.org/10.1007/BF00217197

Peltier, L.J., Hambric, S.A., 2007. Estimating turbulent-boundary-layer wall-pressure spectra from CFD RANS solutions. J. Fluids Struct. 23, 920-937. https://doi.org/10.1016/j.jfluidstructs.2007.01.003

Pereira, F.S., Eca, L., Vaz, G., 2017. Verification and Validation exercises for the flow around the KVLCC2 tanker at model and full-scale Reynolds numbers. Ocean Eng. 129, 133-148. https://doi.org/10.1016/j.oceaneng.2016.11.005

Pethiyagoda, R., McCue, S.W., Moroney, T.J., 2017. Spectrograms of ship wakes: Identifying linear and nonlinear wave signals. J. Fluid Mech. 811, 189-209. https://doi.org/10.1017/jfm.2016.753

Pethiyagoda, R., Moroney, T.J., Macfarlane, G.J., Binns, J.R., McCue, S.W., 2018. Timefrequency analysis of ship wave patterns in shallow water: modelling and experiments. Ocean Eng. 158, 123-131. https://doi.org/10.1016/j.oceaneng.2018.01.108

Piomelli, U., Balaras, E., 2002. Wall Layer Models for Large Eddy Simulations. Annu. Rev. Fluid Mech. 34, 349-374. https://doi.org/10.1146/annurev.fluid.34.082901.144919

Ponkratov, D., 2016. Lloyd's Register workshop on ship scale hydrodynamics, in: Ponkratov, D. (Ed.), 2016 Workshop on Ship Scale Hydrodynamic Computer Simulation. p. 2016. https://doi.org/10.1002/ejoc.201200111

Quérard, A., Temarel, P., Turnock, S.R., 2008. Influence of viscous effects on the hydrodynamics of ships-like sections undergoing symmetric and anti-symmetric motions, using RANS, in: Proceedings of the ASME 27th International Confer Ence on Offshore Mechanics and Arctic Engineering OMAE2008, Estoril, Portugal. pp. 1-10. https://doi.org/10.1115/OMAE2008-57330

Raven, H., van der Ploeg, A., Starke, A.R., Eca, L., 2008. Towards a CFD-based prediction 
of ship performance - progress in predicting full-scale resistance and scale effects. Int. J. Marit. Eng. 150.

Richardson, L.F., 1911. The Approximate Arithmetical Solution by Finite Differences of Physical Problems involving Differential Equations, with an Application to the Stresses in a Masonry Dam. Philos. Trans. th R. Soc. London,Containing Pap. a Math. Phys. Character 210, 307-357.

Roy, C., Blottner, F., 2006. Review and Assessment of Turbulence Models for Hypersonic Flows: 2D/Asymmetric Cases. 44th AIAA Aerosp. Sci. Meet. Exhib. https://doi.org/10.2514/6.2006-713

Saaty, L.T., Bram, J., 1964. Nonlinear mathematics, Vol 12. ed. McGraw-Hill.

Salim, M., Cheah, S.C., 2009. Wall y + strategy for dealing with wall-bounded turbulent flows. Int. MultiConference Eng. Comput. Sci. II, 1-6. https://doi.org/10.1.1.149.722

Schlichting, H., 1979. Boundary-Layer Theory, 7th ed. McGraw-Hill. https://doi.org/10.1007/978-3-662-52919-5

Schoenherr, K., 1932. Resistance of flat surfaces moving through a fluid. Trans. Soc. Nav. Arch. Mar. Eng. 40, 279-313.

Schweighofer, J., 2004. Numerical Investigation of the Turbulent Free-Surface Flow around the Series 60 Ship at Model- and Full-Scale Ship Reynolds Numbers. Yearbok of the Society of Naval Architects. Ger. STG Summer Meet. Pol. 1-10.

Shivachev, E., Khorasanchi, M., Day, A.H., 2017. Trim influence on KRISO container ship (KCS); an experimental and numerical study, in: Proceedings of the ASME 2017 36th International Conference on Ocean, Offshore and Arctic Engineering. pp. 1-7. https://doi.org/10.1115/OMAE2017-61860

Siemens, 2018. Star-CCM+ User Guide version 13.04.

Simonsen, C.D., Otzen, J.F., Joncquez, S., Stern, F., 2013. EFD and CFD for KCS heaving and pitching in regular head waves. J. Mar. Sci. Technol. 18, 435-459. https://doi.org/10.1007/s00773-013-0219-0

Song, S., Demirel, Y.K., Atlar, M., 2019. An investigation into the effect of biofouling on the ship hydrodynamic characteristics using CFD. Ocean Eng. 175, 122-137. https://doi.org/10.1016/j.oceaneng.2019.01.056

Starke, A.R., Drakopoulos, K., Toxopeus, S.L., Turnock, S.R., 2017. RANS-based full-scale power predictions for a general cargo vessel, and comparison with sea-trial results. 7th Int. Conf. Comput. Methods Mar. Eng. Mar. 2017 2017-May, 353-364.

Stern, F., 1985. Effects of Waves on the Boundary Layer of a Surface-Piercing Body.

Stern, F., Wilson, R., Shao, J., 2006. Quantitative V\&V of CFD simulations and certification of CFD codes. Int. J. Numer. Methods Fluids 50, 1335-1355. https://doi.org/10.1002/fld.1090

Stern, F., Yang, J., Wang, Z., Sadat-Hosseini, H., Mousaviraad, M., 2013. Computational ship hydrodynamics: Nowadays and way forward. Int. Shipbuild. Prog. 60, 3-105. https://doi.org/10.3233/ISP-130090

Suh, J., Yang, J., Stern, F., 2011. The effect of air-water interface on the vortex shedding 
from a vertical circular cylinder. J. Fluids Struct. 27, 1-22.

https://doi.org/10.1016/j.jfluidstructs.2010.09.001

Tahara, Y., Katsui, T., Himeno, Y., 2002. Computation of Ship Viscous Flow at Full Scale Reynolds Number. J. Soc. Nav. Archit. Japan 92, 89-101.

Telfer, E. V., 1927. Ship resistance similarity. Trans. R. Inst. Nav. Archit. 69, 174-190.

Terziev, M., Tezdogan, T., Oguz, E., Gourlay, T., Demirel, Y.K., Incecik, A., 2018. Numerical investigation of the behaviour and performance of ships advancing through restricted shallow waters. J. Fluids Struct. 76, 185-215.

https://doi.org/10.1016/j.jfluidstructs.2017.10.003

Tezdogan, T., Demirel, Y.K., Kellett, P., Khorasanchi, M., Incecik, A., Turan, O., 2015. Fullscale unsteady RANS CFD simulations of ship behaviour and performance in head seas due to slow steaming. Ocean Eng. 97, 186-206. https://doi.org/10.1016/j.oceaneng.2015.01.011

Tezdogan, T., Incecik, A., Turan, O., 2016a. Full-scale unsteady RANS simulations of vertical ship motions in shallow water. Ocean Eng. 123, 131-145. https://doi.org/10.1016/j.oceaneng.2016.06.047

Tezdogan, T., Incecik, A., Turan, O., Kellett, P., 2016b. Assessing the Impact of a Slow Steaming Approach on Reducing the Fuel Consumption of a Containership Advancing in Head Seas. Transp. Res. Procedia 14, 1659-1668. https://doi.org/10.1016/j.trpro.2016.05.131

Toki, N., 2008. Investigation on Correlation Lines through the Analyses of Geosim Model Test Results. J. Japan Soc. Nav. Archit. Ocean Eng. 8, 71-79.

Townsin, R.L., 1971. The viscous drag of a "Victory" model-Results from wake and wave pattern measurements. Trans. RINA 113, 307-321.

Townsin, R.L., 1968. Viscous drag from a wake survey. Measurements in the wake of a 'Lucy Ashton' mode. Trans. RINA 110.

Troesch, A., Beck, R.F., 1974. Experiments on ship motions in shallow water.

Tropea, C., Yarin, A.L., Foss, J.F., 2007. Springer handbook of experimental fluid mechanics, Springer Berlin, Heidelberg. https://doi.org/10.1007/978-3-540-30299-5

Tuck, E.O., Lazauskas, L. V, 2008. Drag on a ship and Michell's integral, in: 22nd Int. Congress of Theoretical and Applied Mechanics, Adelaide, South Australia, August.

UNFCCC, 1998. Kyoto Protocol To the United Nations Framework Kyoto Protocol To the United Nations Framework, United Nations. https://doi.org/10.1111/1467-9388.00150

van Mannen, J.D., van Oossanem, P., 1988. Principles of Naval Architecture. The Society of Naval Architects and Marine Engineers, Jersey.

Visonneau, M., 2005. A Step Towards the Numerical Simulation of Viscous Flows Around Ships at Full-Scale. Mar. CFD.

Wang, J., Yu, H., Zhang, Y., Xiong, X., 2016. CFD-based method of determining form factor $\mathrm{k}$ for different ship types and different drafts. J. Mar. Sci. Appl. 15, 236-241. https://doi.org/10.1007/s11804-016-1372-8 
Wang, Z.Z., Xiong, Y., Shi, L.P., Liu, Z.H., 2015. A numerical flat plate friction line and its application. J. Hydrodyn. 27, 383-393. https://doi.org/10.1016/S1001-6058(15)60496-6

White, F., 2010. Fluid Mechanics. McGraw-Hill,New York 862. https://doi.org/10.1111/j.1549-8719.2009.00016.x.Mechanobiology

White, F., 2006. Viscous fluid flow, 3rd ed. McGraw-Hill.

Xing, T., Stern, F., 2010. Factors of Safety for Richardson Extrapolation. J. Fluids Eng. 132, 061403. https://doi.org/10.1115/1.4001771 